\title{
Discovery of Incednine as a Potent Modulator of the Anti- apoptotic Function of Bcl-xL from Microbial Origin
}

Yushi Futamura, ${ }^{\dagger}$ Ryuichi Sawa, ${ }^{\star}$ Yoji Umezawa, ${ }^{\star}$ Masayuki Igarashi, ${ }^{*}$ Hikaru Nakamura, ${ }^{*}$ Kimiko Hasegawa, ${ }^{\S}$ Mikio Yamasaki, ${ }^{\S}$ Etsu Tashiro, ${ }^{\dagger}$ Yoshikazu Takahashi, ${ }^{\ddagger}$ Yuzuru Akamatsu, ${ }^{\ddagger}$ and Masaya Imoto* ${ }^{\dagger}$

$\dagger$ Department of Biosciences and Informatics, Faculty of Science and Technology, Keio University, 3-14-1 Hiyoshi, Kohoku-ku, Yokohama 223-8522, Japan, \$Microbial Chemistry Research Center, 3-14-23 Kamiosaki, Shinagawa-ku, Tokyo 141-0021, Japan, and §Rigaku Corporation, 3-9-12 Matsubaracho, Akishima-shi, Tokyo 196-8666, Japan

E-mail: imoto@bio.keio.ac.jp

\section{Experimental Section}

$\begin{array}{ll}\text { (i) Chemistry } & \text { S2 }\end{array}$

$\begin{array}{lr}\text { (ii) Biological Activity } & \text { S4 }\end{array}$

$\begin{array}{ll}\text { References } & \text { S5 }\end{array}$

\section{Supplementary Figures}

(i) Chemistry $\quad$ S6

$\begin{array}{lr}\text { (ii) Biological Activity } & \text { S23 }\end{array}$ 


\section{Experimental Section}

(i) Chemistry

\section{General}

Melting point was obtained on a Yanaco micro melting point apparatus. Optical rotation was obtained on a JASCO P1030 spectropolarimeter using a micro-cell (light path $10 \mathrm{~cm}$ ). IR spectrum was taken on a Horiba FT-210 spectrophotometer in a KBr disc. UV spectra were recorded on Hitachi U-2800 spectrophotometer. CD spectra were taken on a JASCO J-720 CD spectropolarimeter. ESIMS and HRESIMS were measured on a Thermo Fisher SCIENTIFIC LTQ Orbitrap mass spectrometer. ${ }^{1} \mathrm{H},{ }^{13} \mathrm{C}$, and 2D-NMR spectra were recorded on a JEOL JMN-ECA600 spectrometer using TMS as internal standard.

\section{Fermentation and Isolation of Incednine (1)}

A slant culture of strain ML694-90F3 was inoculated into a 500-mL Erlenmeyer flask containing 110 $\mathrm{mL}$ of $2.0 \%$ galactose, $2.0 \%$ dextrin, $1.0 \%$ Bacto-soytone, $0.5 \%$ corn steep liquor, $0.2 \%\left(\mathrm{NH}_{4}\right)_{2} \mathrm{SO}_{4}$, $0.2 \% \mathrm{CaCO}_{3}$, and a drop of silicone oil (adjusted to $\mathrm{pH} 7.4$ before sterilization). The flask was shaken on a rotary shaker $(180 \mathrm{rpm})$ at $27^{\circ} \mathrm{C}$ for 3 days. This seed culture was transferred to 18 flasks with the same medium and these flasks were shaken on a rotary shaker in the same culture conditions. Seed cultures were also transferred into a 200-liter jar fermentor containing $100 \mathrm{~L}$ of production medium consisting of $0.5 \%$ glucose, $0.5 \%$ glycerol, $0.15 \%$ sodium L-glutamate, $0.5 \%$ Ajipron, and $0.1 \% \mathrm{CaCO}_{3}$ (adjusted to $\mathrm{pH} 7.4$ before sterilization). The production of incednine was carried out at $27^{\circ} \mathrm{C}$ for 3 days under aeration of $100 \mathrm{~L} /$ minute and agitation at a rate of $200 \mathrm{rpm}$.

Anhydrous $\mathrm{Na}_{2} \mathrm{SO}_{4}(5 \mathrm{~kg})$ were added to the culture broth $(100 \mathrm{~L})$, and stored at $10^{\circ} \mathrm{C}$ under basic conditions ( $\mathrm{pH}$ 9) for a few days. The precipitate, including mycelial cake, in the broth was filtered out and the precipitate was extracted with $\mathrm{CHCl}_{3}: \mathrm{MeOH}(1: 1,40 \mathrm{~L})$. The extract was concentrated in vacuo to dryness. The residue was dissolved in $\mathrm{CHCl}_{3}: \mathrm{MeOH}: \mathrm{H}_{2} \mathrm{O}(5: 6: 4,1.6 \mathrm{~L})$ and partitioned. One eighth volume of the organic layer $(80 \mathrm{~mL})$ was applied to Centrifugal liquid-liquid Partition Chromatography (CPC; Senshu Scientific Co., LTD. CPC240 apparatus) using a solvent system of $\mathrm{CHCl}_{3}: \mathrm{MeOH}_{2} \mathrm{H}_{2} \mathrm{O}$ (5:6:4) in the descending mode. The active fractions were eluted with the lower layer of the solvent system, collected, and evaporated under reduced pressure to yield a yellow powder $(1.47 \mathrm{~g})$. The residue was injected into a $2^{\text {nd }} \mathrm{CPC}$ using a solvent system of $\mathrm{CHCl}_{3}: \mathrm{MeOH}: 5 \mathrm{mM} \mathrm{HCl}$ aq. (5:6:4) in the descending mode. After washing $1320 \mathrm{~mL}$ of the lower layer, incednine was retained in the immobile phase, and then eluted with the upper layer. Fractions containing pure incednine were collected, and $\mathrm{H}_{2} \mathrm{O}$ was added to remove the organic solvent. The aqueous solution was lyophilized to obtain a pale yellow powder as a $\mathrm{HCl}$ salt of incednine (1) $\left(236.2 \mathrm{mg}\right.$, total $1.89 \mathrm{~g} / 100 \mathrm{~L}$ culture). m.p. 122-124 ${ }^{\circ}$; $[\alpha]_{\mathrm{D}}{ }^{20}:-702.3^{\circ}(c 0.2, \mathrm{MeOH}) ;{ }^{1} \mathrm{H}$ and ${ }^{13} \mathrm{C}$ NMR see Table S1; IR (KBr): $v=3440,2980,2930,1650$, 1620, 1580, 1510, 1460, 1160, 1080, 990, $960 \mathrm{~cm}^{-1}$; UV/VIS $(\mathrm{MeOH}): \lambda_{\max }(\log \varepsilon)=356.0(4.64), 322.5$ (5.38), 309.5 (5.23), $294.5 \mathrm{~nm}$ (4.88); HRESIMS m/z: 738.4691 [(M+H) calcd. for $\mathrm{C}_{42} \mathrm{H}_{64} \mathrm{~N}_{3} \mathrm{O}_{8}$, $738.4688]$.

\section{Isolation of Incednine Aglycon (2)}

Fractions containing compound 2 were found in the elution of the descending mode in the $2^{\text {nd }} \mathrm{CPC}$ described above and neutralized with saturated $\mathrm{NaHCO}_{3}$ aq. The obtained lower layer was evaporated in vacuo to dryness. The residue $(1.16 \mathrm{~g})$ was applied to silica gel chromatography, washed with $\mathrm{CHCl}_{3}$, and then eluted with $\mathrm{CHCl}_{3}: \mathrm{MeOH}$ (100:1). Fractions containing compound 2 were collected and evaporated in vacuo to give a pale yellow solid. The solid was washed with toluene:acetone (10:1) and the precipitate was filtered to give a pale yellow powder of pure $2(18.1 \mathrm{mg}$, total $156.4 \mathrm{mg} / 100 \mathrm{~L}$ culture). $[\alpha]_{\mathrm{D}}{ }^{20}:-1616.7^{\circ}\left(c 0.1, \mathrm{CHCl}_{3}\right) ;{ }^{1} \mathrm{H}$ and ${ }^{13} \mathrm{C}$ NMR see Table S1; UV/VIS (MeOH): $\lambda_{\max }(\log$ 


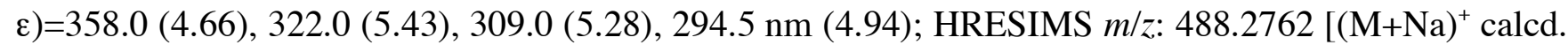
for $\left.\mathrm{C}_{29} \mathrm{H}_{39} \mathrm{NO}_{4} \mathrm{Na}, 488.2771\right]$.

\section{Preparation of Incednine aglycon (2) 11-O-MTPA Ester}

Incednine aglycon $(10.0 \mathrm{mg}, 0.02 \mathrm{mmol})$ was dissolved in anhydrous pyridine $(1 \mathrm{~mL}),(+)-\alpha-$ methoxy- $\alpha$-(trifluoromethyl)phenylacetyl chloride ((+)-MTPA-Cl, $40 \mu \mathrm{L}, 0.24 \mathrm{mmol})$ was added, and the mixture was allowed to stand at RT for $4 \mathrm{~h}$. The reaction mixtures were added to $\mathrm{H}_{2} \mathrm{O}(10 \mu \mathrm{L})$ on ice and evaporated in vacuo to dryness. The residues were purified by silica gel column chromatography (toluene:ethyl acetate $=10: 1)$ to give the $R$-MTPA ester of $2(3,13.7 \mathrm{mg}$, yield=92.4\%). The $S$-MTPA ester of $2(4,12.9 \mathrm{mg}$, yield=86.9\%) was obtained from incednine aglycon $(10.0 \mathrm{mg})$ and $(-)-\alpha-$ methoxy- $\alpha$-(trifluoromethyl)phenylacetyl chloride ((-)-MTPA-Cl, $40 \mu \mathrm{L}, 0.24 \mathrm{mmol}$ ) in a manner similar to that described above. Compound 3: amorphous pale yellow powder; $[\alpha]_{\mathrm{D}}{ }^{20}:-719.5^{\circ}(c 0.2$, $\left.\mathrm{CHCl}_{3}\right) ;{ }^{1} \mathrm{H}$ and ${ }^{13} \mathrm{C}$ NMR see Table S2; HRESIMS $m / z: 704.3169\left[(\mathrm{M}+\mathrm{Na})^{+}\right.$calcd. for $\mathrm{C}_{39} \mathrm{H}_{46} \mathrm{NO}_{6} \mathrm{~F}_{3} \mathrm{Na}$, 704.3169]. Compound 4: amorphous pale yellow powder; $[\alpha]_{\mathrm{D}}{ }^{20}:-886.9^{\circ}\left(c 0.2, \mathrm{CHCl}_{3}\right) ;{ }^{1} \mathrm{H}$ and ${ }^{13} \mathrm{C}$ NMR see Table S2; HRESIMS m/z: 704.3162 [(M+Na) ${ }^{+}$calcd. for $\left.\mathrm{C}_{39} \mathrm{H}_{46} \mathrm{NO}_{6} \mathrm{~F}_{3} \mathrm{Na}, 704.3169\right]$.

\section{Methyl N-(4-bromobenzoyl)-2,3,4,6-tetradeoxy-4-methylamino- $\beta$-D-erythro-hexopyranoside (5)}

4-Bromobenzoyl chloride $(29.0 \mathrm{mg}, 0.13 \mathrm{mmol})$ was added to a solution of incednine (1) $(52.0 \mathrm{mg}$, $0.07 \mathrm{mmol})$ in anhydrous pyridine $(5 \mathrm{~mL})$ and the mixture was stirred for $16 \mathrm{~h}$ at $\mathrm{RT} . \mathrm{H}_{2} \mathrm{O}(10 \mu \mathrm{L})$ was added and the whole mixture was concentrated to dryness. The residual solid was partitioned with 200 $\mathrm{mL}$ of $\mathrm{CHCl}_{3}: \mathrm{MeOH}: \mathrm{NaHCO}_{3}$ aq. (5:6:4). The lower layer was washed with the upper layer of $\mathrm{CHCl}_{3}: \mathrm{MeOH}: \mathrm{H}_{2} \mathrm{O}(5: 6: 4)$ and evaporated in vacuo to yield semi-purified 4"- $N$-4-bromobenzoyl incednine as a yellow powder $(72.3 \mathrm{mg})$. Without further purification, the compound was dissolved in anhydrous $\mathrm{CH}_{2} \mathrm{Cl}_{2}(5 \mathrm{~mL})$ and $10 \%$ methanolic hydrogen chloride $(6 \mathrm{~mL})$ and stirred at $\mathrm{RT}$ for $2.5 \mathrm{~h}$. The reaction mixtures were added to $400 \mathrm{~mL}$ of $\mathrm{CHCl}_{3}: \mathrm{MeOH}: \mathrm{NaHCO}_{3}$ aq. (5:6:4). The lower layer containing $\alpha / \beta$-methyl glycoside was washed with the upper layer of $\mathrm{CHCl}_{3}: \mathrm{MeOH}: \mathrm{H}_{2} \mathrm{O}(5: 6: 4)$ and evaporated in vacuo to yield a dark brown powder $(67.8 \mathrm{mg})$. The residue was purified by HPLC (Senshu Pak Pegasil ODS $30 \times 250 \mathrm{~mm}$ ) and eluted with $\mathrm{MeOH}: 40 \mathrm{mM} \mathrm{KH} \mathrm{PO}_{4}$ aq. (70:30) to afford a mixture of $\alpha / \beta$-methyl glycoside. Finally, the mixture was purified by preparative TLC (hexane:ethyl acetate $=1: 1$ ) to give $13.8 \mathrm{mg}$ of $\alpha$-anomer and $3.8 \mathrm{mg}$ of $\beta$-anomer (5). Compound $\mathbf{5}$ was recrystallized with hexane-acetone to give colorless needles. m.p. $132{ }^{\circ} \mathrm{C} ;[\alpha]_{\mathrm{D}}{ }^{20}:-35.7^{\circ}\left(c 0.2, \mathrm{CHCl}_{3}\right) ;{ }^{1} \mathrm{H}$ and ${ }^{13} \mathrm{C}$ NMR see Table S3; HRESIMS m/z: 364.0507 [(M+Na) ${ }^{+}$calcd. for $\mathrm{C}_{15} \mathrm{H}_{20} \mathrm{NO}_{3} \mathrm{BrNa}, 364.0519$ ].

X-ray Crystallography of Methyl N-(4-bromobenzoyl)-2,3,4,6-tetradeoxy-4-methylamino- $\beta$-D-erythrohexopyranoside (5)

A colorless platelet crystal of $\mathrm{C}_{15} \mathrm{H}_{20} \mathrm{NO}_{3} \mathrm{Br}$ having approximate dimensions of $0.23 \times 0.23 \times 0.06 \mathrm{~mm}$ was mounted on a glass fiber. All measurements were made on a Rigaku R-AXIS RAPID II imaging plate area detector with graphite monochromated $\mathrm{CuK \alpha}$ radiation. Indexing was performed from 3 oscillations that were exposed for $30 \mathrm{sec}$. The crystal-to-detector distance was $127.40 \mathrm{~mm}$. Cell constants and an orientation matrix for data collection corresponded to a primitive monoclinic cell with dimensions: $a=8.41004(15) \AA, b=10.48964(19) \AA, c=9.31450(17) \AA, \beta=107.8149(8)^{\circ}, V=782.31(2) \AA^{3}$. The data were collected at a temperature of $296 \mathrm{~K}$ to a maximum $2 \theta$ value of $136.1^{\circ}$. Of the 8907 reflections that were collected, 2505 were unique $\left(R_{\text {int }}=0.059\right)$; equivalent reflections were merged. The linear absorption coefficient, $\mu$, for $\mathrm{CuK \alpha} \alpha$ radiation is $36.456 \mathrm{~cm}^{-1}$. An empirical absorption correction was applied which resulted in transmission factors ranging from 0.593 to 0.804 . A correction for secondary extinction $^{[\mathrm{S1}]}$ was applied (coefficient $=0.000950$ ). The structure was solved by direct methods of SIR2004 ${ }^{[\mathrm{S} 2]}$ and expanded using Fourier techniques of DIRDIF99. ${ }^{[\mathrm{S} 3]}$ The non-hydrogen atoms were refined anisotropically. Hydrogen atoms were refined using riding model. The final cycle of full-matrix 
least-squares refinement ${ }^{[\mathrm{S} 4]}$ on $\mathrm{F}^{2}$ was based on 2505 observed reflections and 186 variable parameters and converged (largest parameter shift was 0.00 times its esd) with unweighted and weighted agreement factors of $R l=0.0362$ and $w R 2=0.1076$, respectively. The maximum and minimum peaks on the final difference Fourier map corresponded to 0.44 and $-0.37 \mathrm{e}^{-} / \AA^{3}$ respectively. The absolute structure was deduced based on Flack parameter, $-0.00(2)$, using 1015 Friedel pairs. ${ }^{[55]}$ All calculations were performed using the CrystalStructure $3.8^{[\mathrm{S} 6]}$ crystallographic software package except for refinement, which was performed using SHELXL-97. ${ }^{[\mathrm{S} 7]}$

\section{Computational Study}

The molecular modeling calculations were carried out in reference to the NMR spectra by using the Discover III module included in Insight II (Accelrys) on Silicon Graphics workstation. The force field used for molecular dynamics (MD) and energy minimization was consistent valence force field (cvff) provided by Accelrys.

\section{(ii) Biological Activity}

\section{Materials}

Inostamycin was isolated from fermentation broth of Streptomyces ${ }^{[\mathrm{S8}]}$. Adriamycin, camptothecin, and taxol were purchased from Sigma Chemical Co. (St. Louis, MO). Vinblastine was obtained from Wako Pure Chemical Industries, Ltd (Tokyo, Japan). HA14-1 was obtained from Calbiochem (San Diego, CA). Anti-Myc monoclonal antibody (9E10) was purchased from Santa Cruz Biotechnology, Inc. (Santa Cruz, CA). Anti-Bcl-xL antibody was obtained from Cell Signaling Technology Inc. (Beverly, MA).

\section{Cell culture, Treatment, and Transfection}

Human SCLC Ms-1 cell lines were cultured in Rosewell Park Memorial Institute media (Nissui, Ohita, Japan) supplemented with $5 \%$ fetal bovine serum, $100 \mathrm{U} / \mathrm{ml}$ penicillin $\mathrm{G}$, and $0.1 \mathrm{mg} / \mathrm{mL}$ kanamycin at $37^{\circ} \mathrm{C}$ in a humidified $5 \% \mathrm{CO}_{2}$ atmosphere. Each of the Ms-1/Neo, Ms-1/Bcl-xL, and Ms-1/Bcl-2 cell lines had been established by stable transfection with pCI-neo vector (Promega, Madison, WI), pCI-Bcl$\mathrm{xL}$, and pCI-Bcl-2, respectively. The doses of various types of anti-tumor drugs, incednine, and the other agents used and the treatment intervals are indicated in the figure captions. Human embryonic kidney 293T (HEK293T) cells were cultured in Dulbecco's modified Eagle's medium (Nissui, Ohita, Japan) supplemented with $10 \%$ fetal bovine serum, $100 \mathrm{U} / \mathrm{mL}$ penicillin $\mathrm{G}$, and $0.1 \mathrm{mg} / \mathrm{mL}$ of kanamycin at $37^{\circ} \mathrm{C}$ in a humidified $5 \% \mathrm{CO}_{2}$ atmosphere. HEK293T cells were transiently transfected using LipofectAMINE ${ }^{\mathrm{TM}}$ reagent (Invitrogen, Carlsbad, CA) according to the manufacturer's instructions.

\section{Cell viability assay}

Drug-treated or untreated cells were stained with trypan blue (Sigma Chemical Co.) and the percentage of viable cells was determined using a hemocytometer. Cell viability (\%) means the ratio of the number of trypan blue-impermeable cells in total cell counts (trypan blue impermeable cell number/total cell number) and Apoptotic rate (\%) vice versa.

\section{Purification of recombinant protein and in vitro binding assay}

Bcl-xL was produced as a GST fusion protein in Escherichia coli DH5 $\alpha$ using a pGEX system (GE Healthcare, UK). GST-Bcl-xL expression was induced with $0.1 \mathrm{mM}$ isopropyl $\beta$-Dthiogalactopyranoside (IPTG) for $3 \mathrm{~h}$ at $37^{\circ} \mathrm{C}$, and purified from the bacterial soluble fraction by affinity chromatography using glutathione-sepharose 4B beads (GE Healthcare, UK). The lysate from Myc- 
Bax-overexpressing HEK293T cells was precleared with glutathione-sepharose 4B beads, and then incubated with purified recombinant GST-Bcl-xL and glutathione-sepharose 4B beads in the presence or absence of drugs for $2 \mathrm{~h}$ at $4^{\circ} \mathrm{C}$. Beads were washed with three times with PBS $^{-}$and eluted with SDS sample buffer. Samples were subjected to SDS-PAGE and the amount of Bax bound to Bcl-xL was measured by immunoblot analysis with anti-Myc antibody.

\section{References}

(S1) Larson, A.C. in Crystallographic Computing, (Ed.: Ahmed, F.R.), Munksgaard, Copenhagen 1970, $291-294$.

(S2) SIR2004: Burla, M.C., Caliandro, R., Camalli, M., Carrozzini, B., Cascarano, G.L., De Caro, L., Giacovazzo, C., Polidori, G., Spagna, R. 2005

(S3) DIRDIF99: Beurskens, P.T., Admiraal, G., Beurskens, G., Bosman, W.P., de Gelder, R., Israel, R., Smits, J.M.M. The DIRDIF-99 program system, Technical Report of the Crystallography Laboratory, University of Nijmegen (The Netherlands) 1999

(S4) Least Squares function minimized: (SHELXL97) $\sum w\left(F_{0}^{2}-F_{c}^{2}\right)^{2}$ where $\mathrm{w}=$ Least Squares weights.

(S5) Flack, H.D. Acta Cryst. 1983, A39, 876-881

(S6) CrystalStructure 3.8: Crystal Structure Analysis Package, Rigaku and Rigaku Americans (2000-2007).

(S7) SHELX97: Sheldrick, G.M. 1997

(S8) Imoto, M., Umezawa, K., Takahashi, Y., Naganawa, H., Iitaka, Y., Nakamura, H., Koizumi, Y., Sasaki, Y., Hamada, M., Sawa, T., Takeuchi, T. J. Nat. Prod. 1990, 53, 825-829.

Complete reference for $(3 \mathrm{~b})$ in the Text.

(3b) Oltersdorf, T., Elmore, S. W., Shoemaker, A. R., Armstrong, R. C., Augeri, D. J., Belli, B. A., Bruncko, M., Deckwerth, T. L., Dinges, J., Hajduk, P. J., Joseph, M. K., Kitada, S., Korsmeyer, S. J., Kunzer, A. R., Letai, A., Li, C., Mitten, M. J., Nettesheim, D. G., Ng, S., Nimmer, P. M., O'Connor, J. M., Oleksijew, A., Petros, A. M., Reed, J. C., Shen, W., Tahir, S. K., Thompson, C. B., Tomaselli, K. J., Wang, B., Wendt, M. D., Zhang, H., Fesik, S. W., Rosenberg, S. H. Nature 2005, 435, 677-981. 


\section{Supplementary Figures}

(i) chemistry

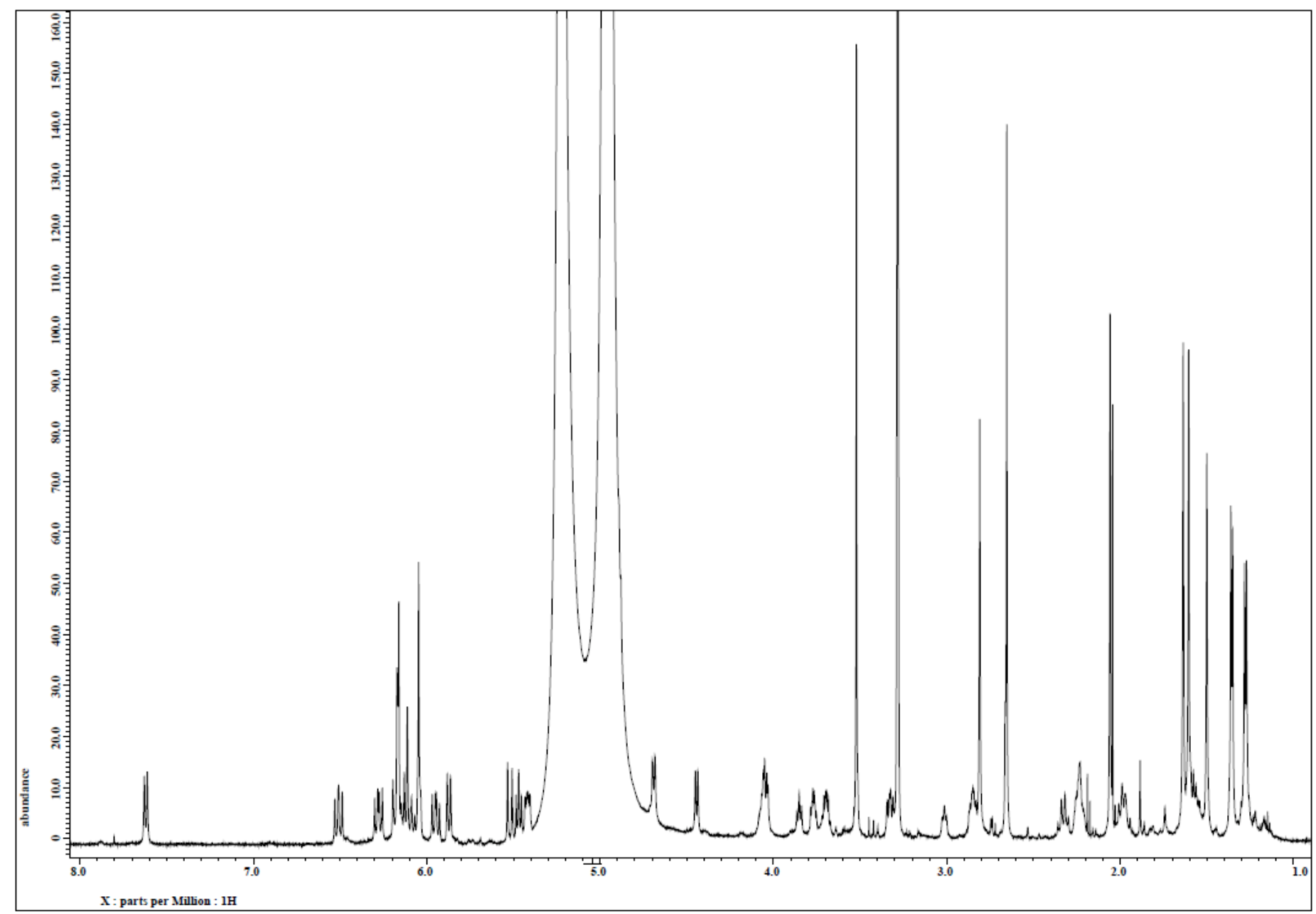

Figure $\mathrm{S} 1^{1} \mathrm{H}$ NMR spectrum of incednine $2 \mathrm{HCl}$ in $\mathrm{CD}_{3} \mathrm{OH}: \mathrm{H}_{2} \mathrm{O}(3: 1)(600 \mathrm{MHz})$ 


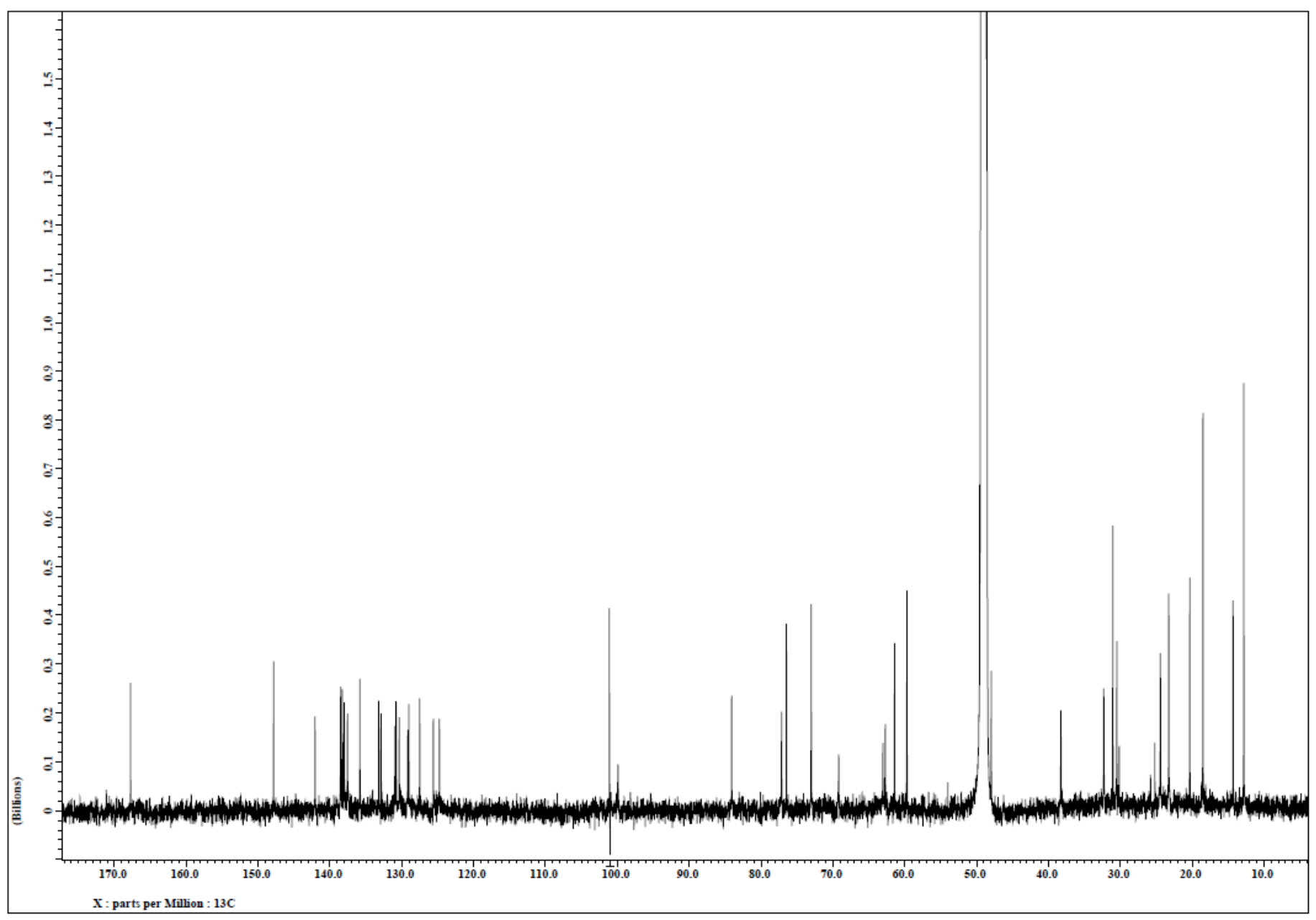

Figure $S 2{ }^{13} \mathrm{C}$ NMR spectrum of incednine $\cdot 2 \mathrm{HCl}$ in $\mathrm{CD}_{3} \mathrm{OH}: \mathrm{H}_{2} \mathrm{O}(3: 1)(150 \mathrm{MHz})$ 


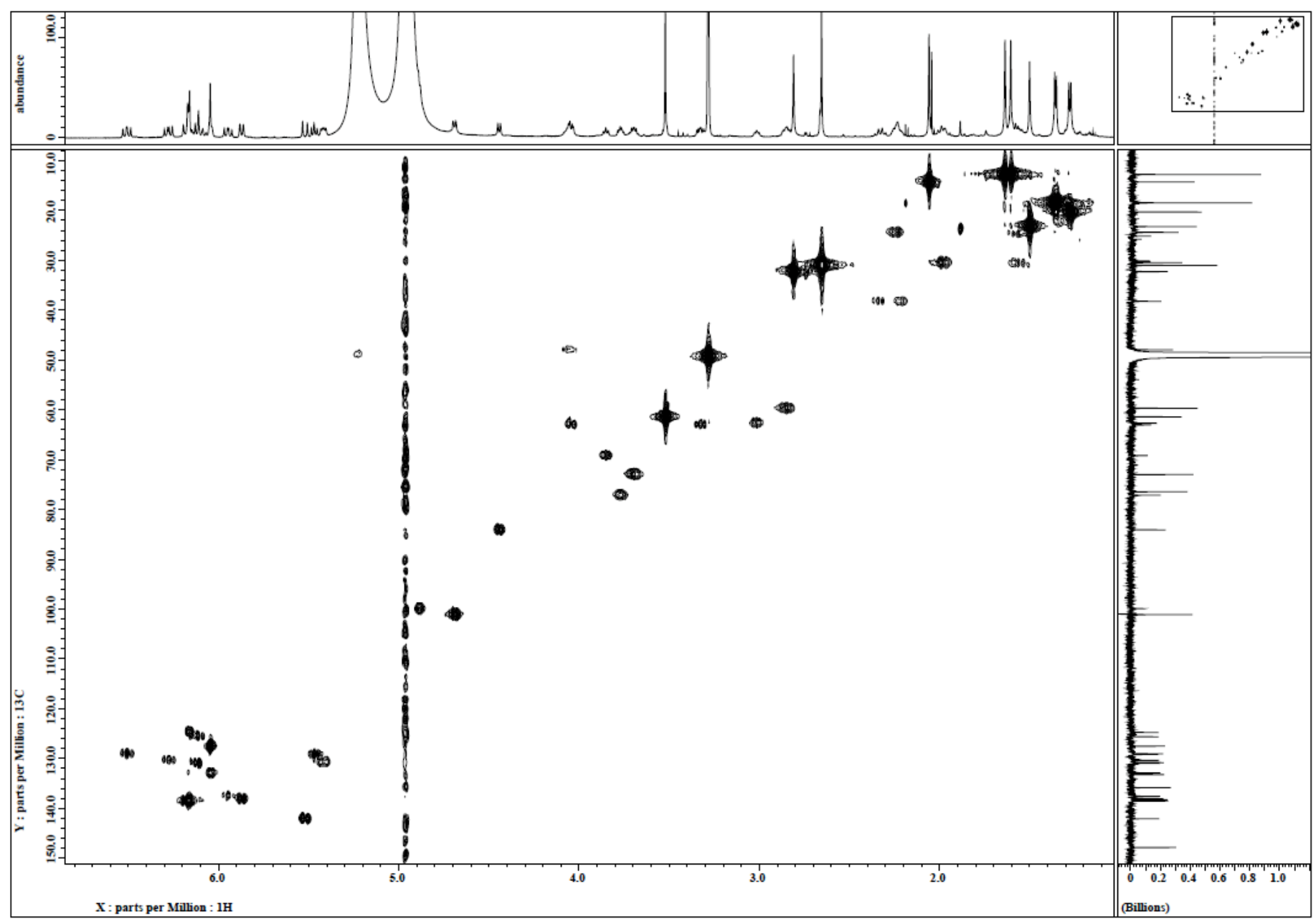

Figure S3 $\mathrm{HMQC}$ spectrum of incednine $2 \mathrm{HCl}$ in $\mathrm{CD}_{3} \mathrm{OH}: \mathrm{H}_{2} \mathrm{O}(3: 1)$ 


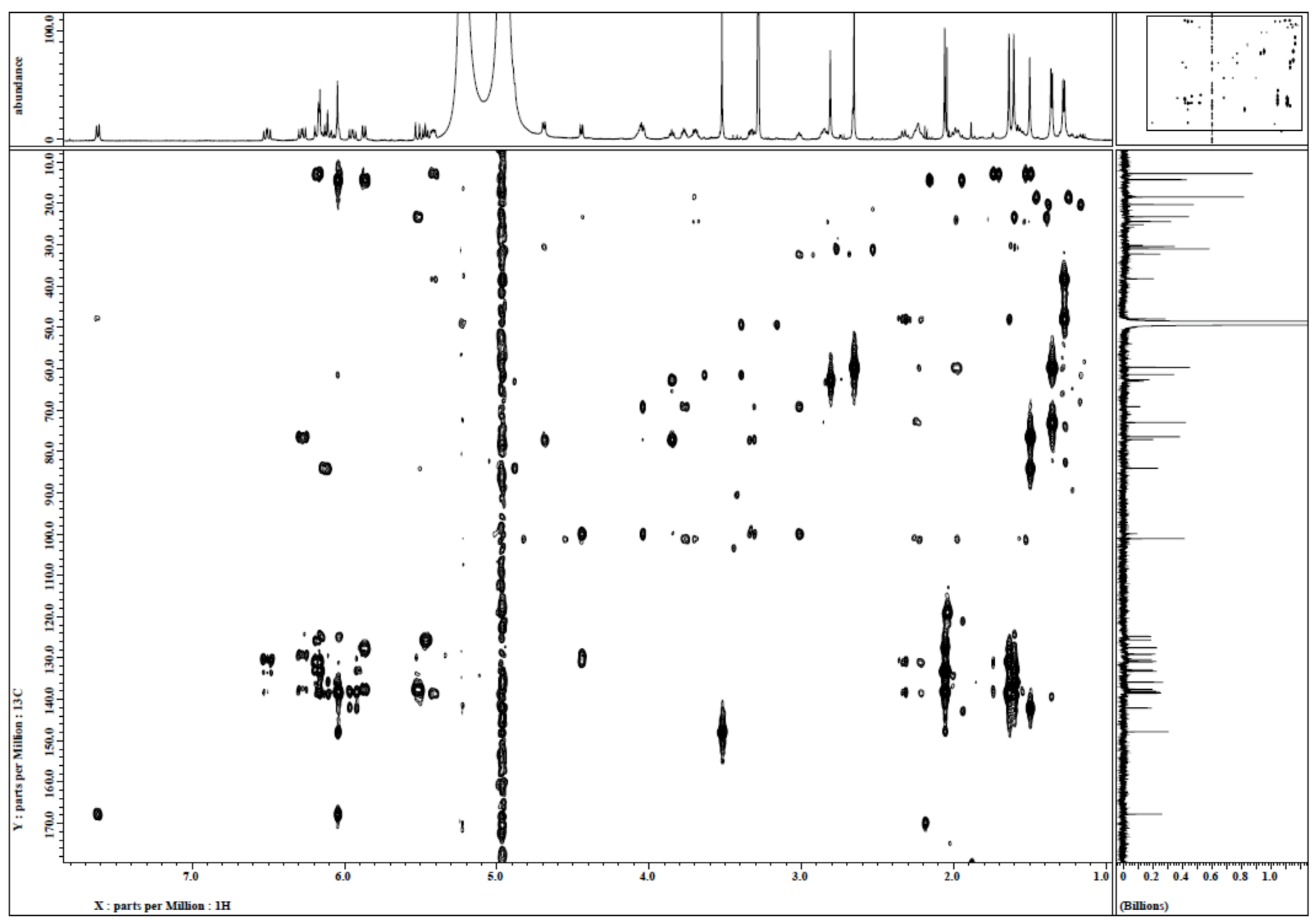

Figure S4 $\mathrm{HMBC}$ spectrum of incednine $\cdot 2 \mathrm{HCl}$ in $\mathrm{CD}_{3} \mathrm{OH}: \mathrm{H}_{2} \mathrm{O}(3: 1)$ 


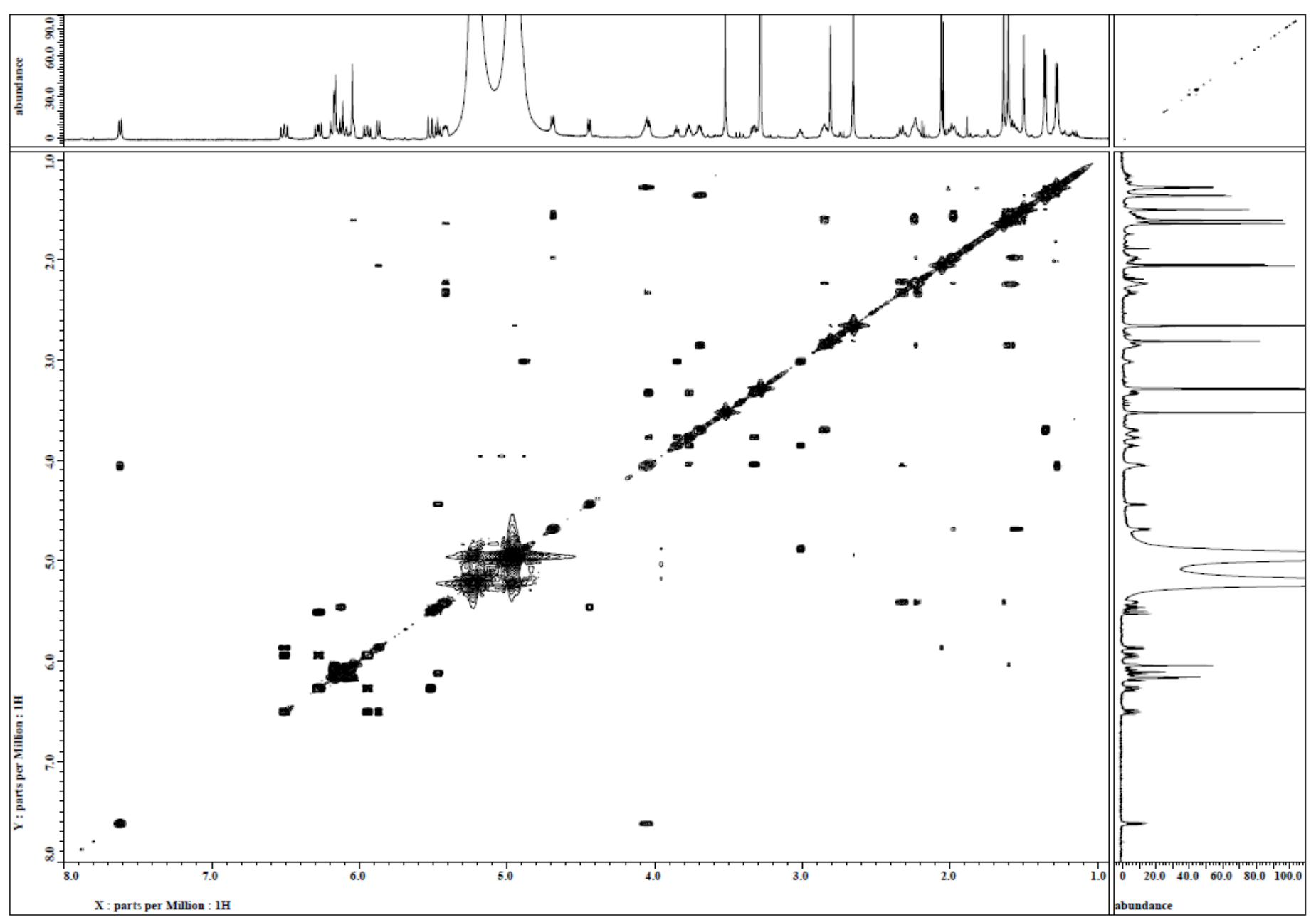

Figure $S 5{ }^{1} \mathrm{H}-{ }^{-1} \mathrm{H}$ COSY spectrum of incednine $2 \mathrm{HCl}$ in $\mathrm{CD}_{3} \mathrm{OH}: \mathrm{H}_{2} \mathrm{O}(3: 1)$ 


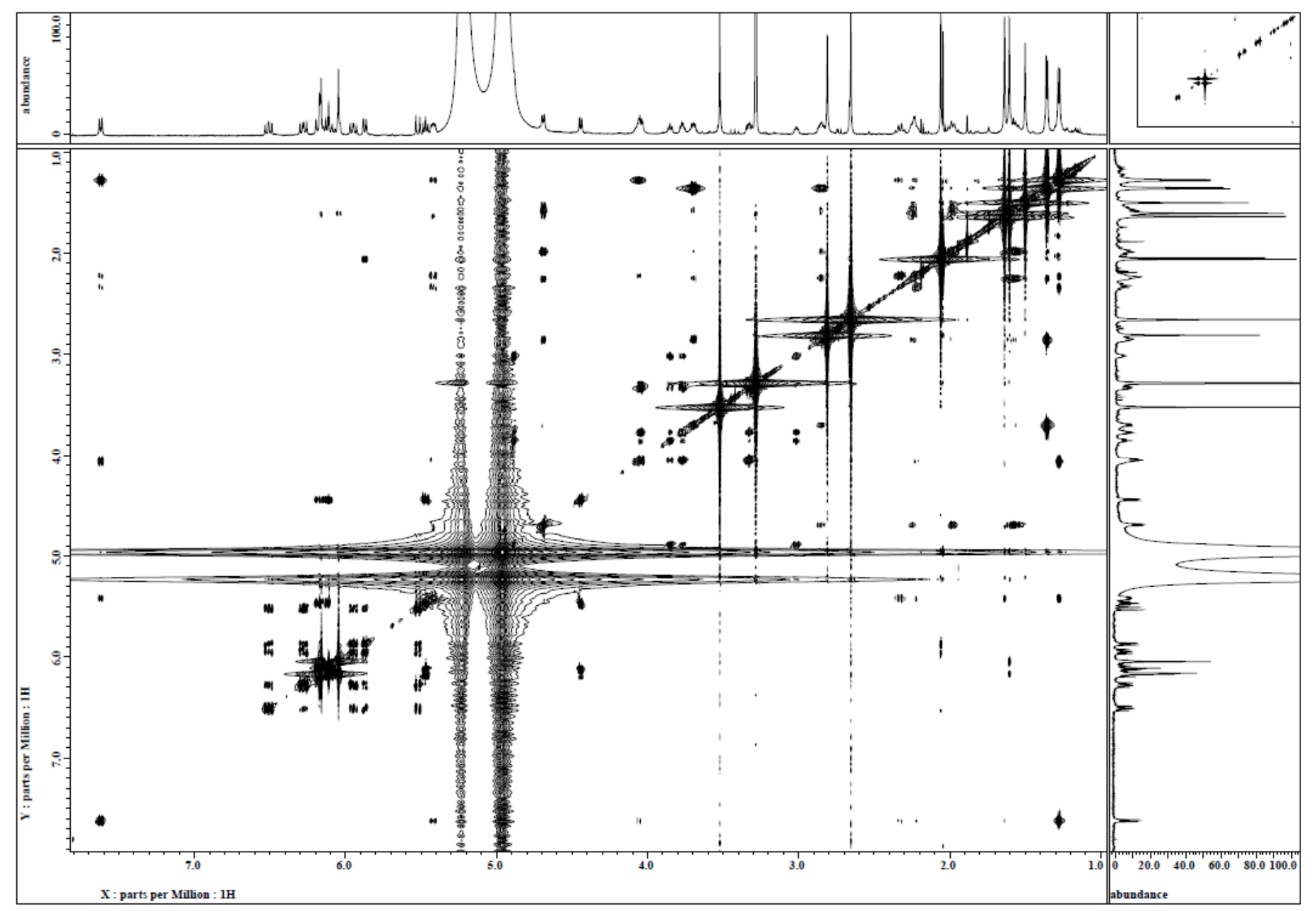

Figure S6 2D TOCSY spectrum of incednine $2 \mathrm{HCl}$ in $\mathrm{CD}_{3} \mathrm{OH}: \mathrm{H}_{2} \mathrm{O}(3: 1)$ 


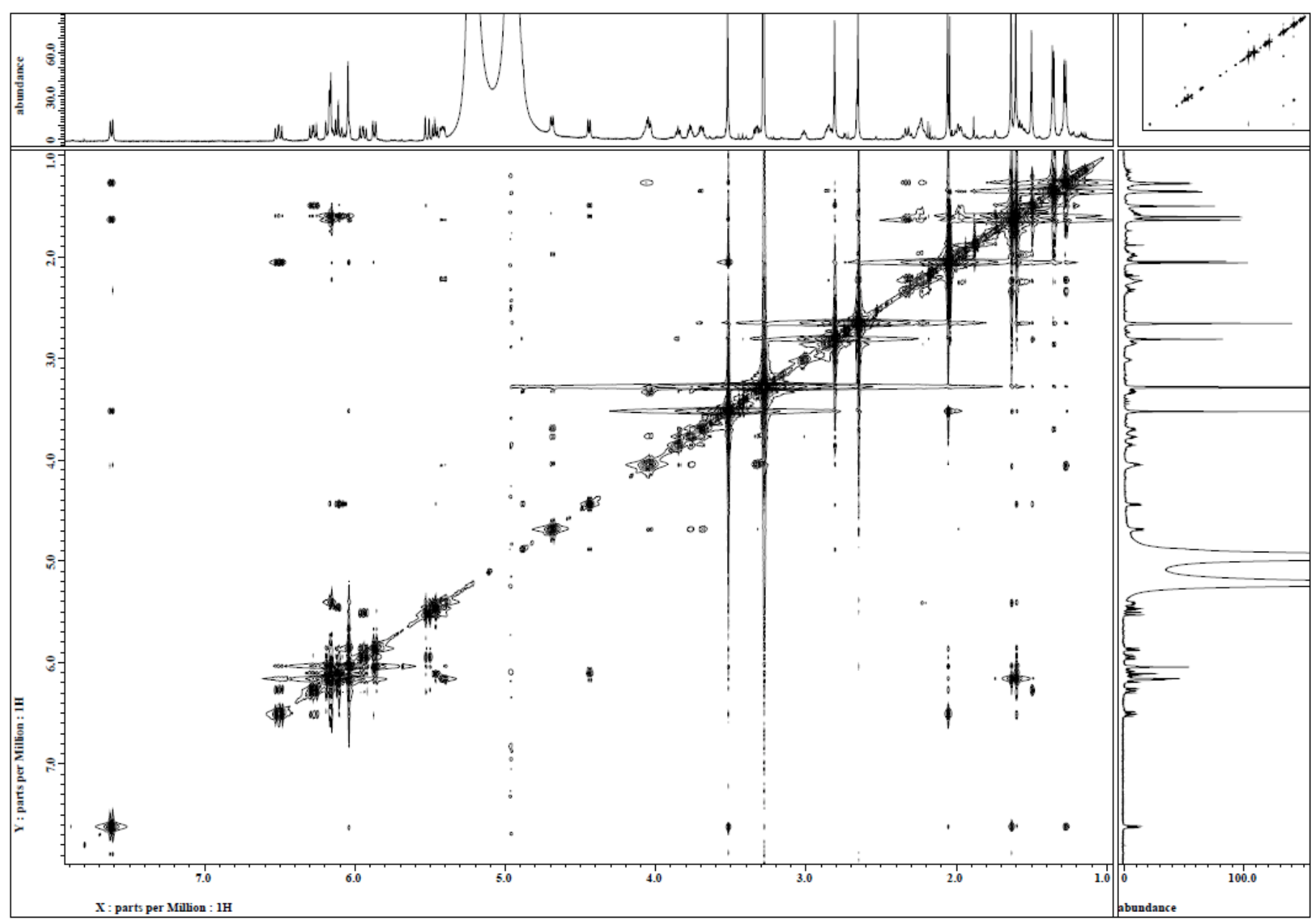

Figure S7 NOESY spectrum of incednine $2 \mathrm{HCl}$ in $\mathrm{CD}_{3} \mathrm{OH}: \mathrm{H}_{2} \mathrm{O}(3: 1)$ 


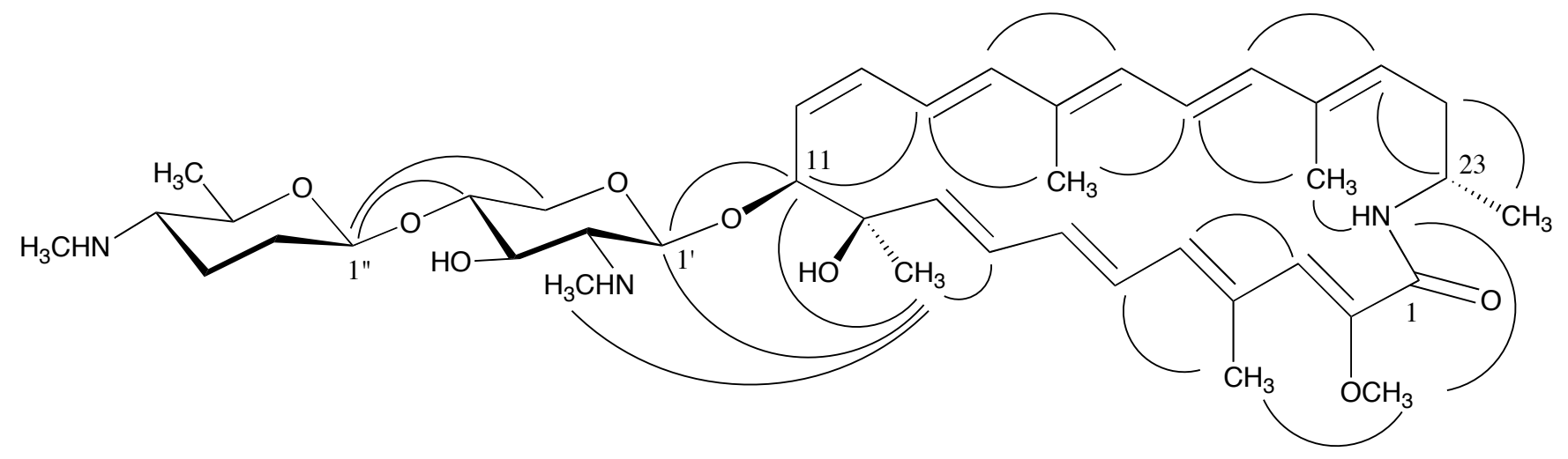

Figure $\mathbf{S} 8$ Selected NOE correlations of incednine $\cdot 2 \mathrm{HCl}$ 


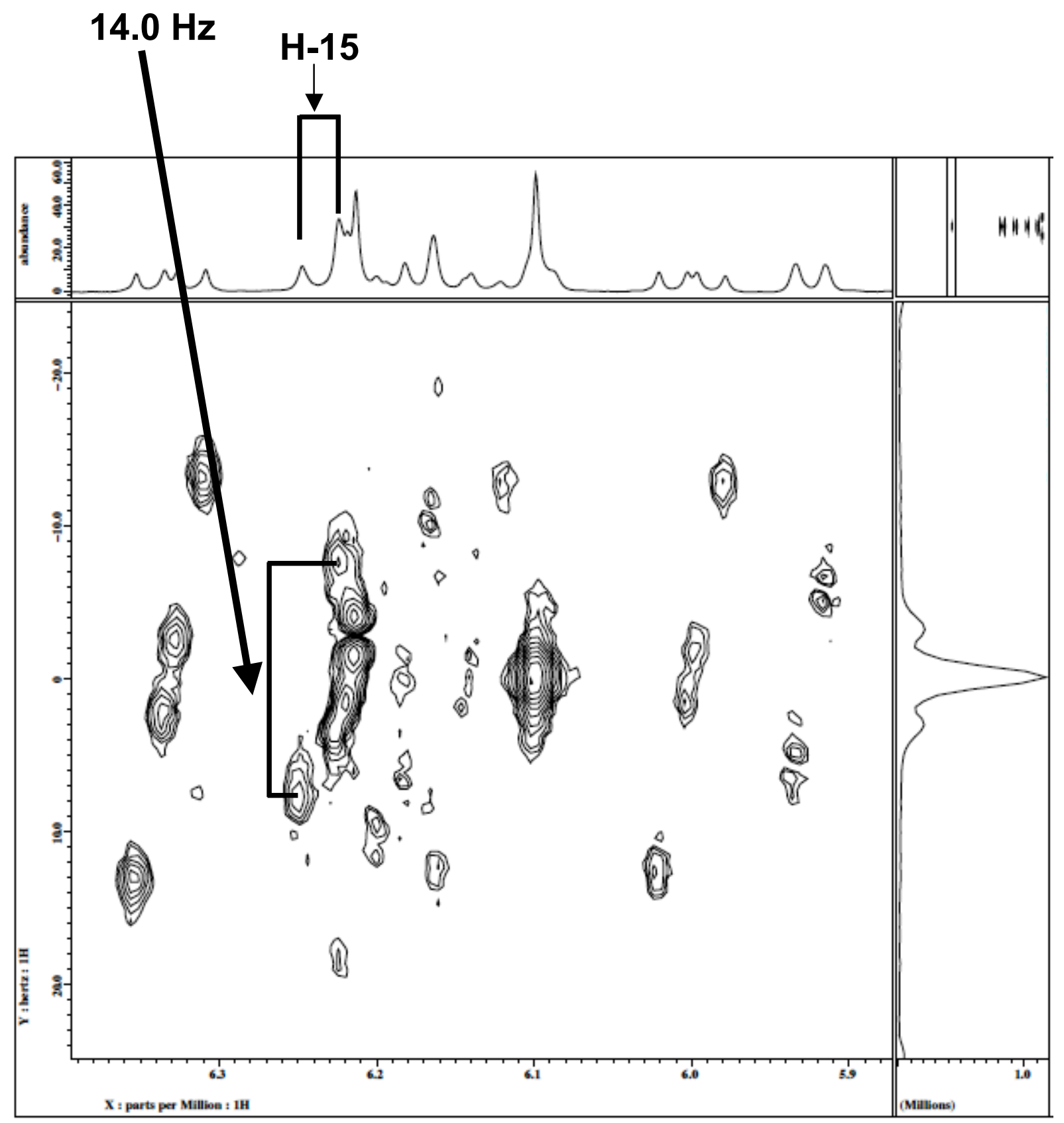

Figure $S 9{ }^{1} \mathrm{H}-{ }^{1} \mathrm{H}$ J-resolve spectrum of incednine $\cdot 2 \mathrm{HCl}$ in $\mathrm{CD}_{3} \mathrm{OH}: \mathrm{H}_{2} \mathrm{O}(3: 1)$ 
Table $S 1{ }^{1} \mathrm{H}$ and ${ }^{13} \mathrm{C}$ NMR data of incednine $\cdot 2 \mathrm{HCl}$ (1) and its aglycon (2)

\begin{tabular}{|c|c|c|c|c|}
\hline \multirow[b]{2}{*}{ No. } & \multicolumn{2}{|c|}{$1\left(\mathrm{CD}_{3} \mathrm{OH}: \mathrm{H}_{2} \mathrm{O}=3: 1,-5^{\circ} \mathrm{C}\right)$} & \multicolumn{2}{|c|}{$2\left(\mathrm{CDCl}_{3}: \mathrm{CD}_{3} \mathrm{OD}=1: 1,25^{\circ} \mathrm{C}\right)$} \\
\hline & $\delta_{\mathrm{C}}$ & $\delta_{\mathrm{H}}($ multiplicity, $J[\mathrm{~Hz}])$ & $\delta_{\mathrm{C}}$ & $\delta_{\mathrm{H}}($ multiplicity, $J[\mathrm{~Hz}])$ \\
\hline 1 & $167.7(\mathrm{~s})$ & & $167.0(\mathrm{~s})$ & \\
\hline 2 & 147.9 (s) & & $147.4(\mathrm{~s})$ & \\
\hline 3 & $127.5(d)$ & $6.05(1 \mathrm{H}, \mathrm{brs})$ & $126.9(d)$ & $6.15(1 \mathrm{H}, \mathrm{brs})$ \\
\hline 4 & $133.2(\mathrm{~s})$ & & $132.3(\mathrm{~s})$ & \\
\hline 5 & $138.0(d)$ & $5.87(1 \mathrm{H}, \mathrm{d}, 11.6)$ & 137.7 (d) & $5.95(1 \mathrm{H}, \mathrm{d}, 11.4)$ \\
\hline 6 & $129.0(d)$ & $6.51(1 \mathrm{H}, \mathrm{dd}, 11.6,14.4)$ & $128.0(d)$ & $6.43(1 \mathrm{H}, \mathrm{dd}, 11.4,14.8)$ \\
\hline 7 & $137.6(d)$ & $5.95(1 \mathrm{H}, \mathrm{dd}, 10.8,14.4)$ & $137.3(d)$ & $6.02(1 \mathrm{H}, \mathrm{dd}, 10.9,14.8)$ \\
\hline 8 & $130.4(d)$ & $6.28(1 \mathrm{H}, \mathrm{dd}, 10.8,15.8)$ & $129.0(d)$ & $6.19(1 \mathrm{H}, \mathrm{dd}, 10.9,15.6)$ \\
\hline 9 & $142.1(d)$ & $5.52(1 \mathrm{H}, \mathrm{d}, 15.8)$ & $143.3(d)$ & $5.65(1 \mathrm{H}, \mathrm{d}, 15.6)$ \\
\hline 10 & 76.5 (s) & & 76.1 (s) & \\
\hline 11 & $84.1(d)$ & $4.44(1 \mathrm{H}, \mathrm{d}, 9.0)$ & 75.9 (d) & $4.22(1 \mathrm{H}, \mathrm{d}, 9.0)$ \\
\hline 12 & $129.2(d)$ & $5.47(1 \mathrm{H}, \mathrm{t}, 9.0)$ & $130.7(d)$ & $5.45(1 \mathrm{H}, \mathrm{t}, 9.0)$ \\
\hline 13 & $130.1(d)$ & $6.13(1 \mathrm{H}, \mathrm{m})$ & $125.4(d)$ & $6.10(1 \mathrm{H}, \mathrm{m})$ \\
\hline 14 & $125.6(d)$ & $6.09(1 \mathrm{H}, \mathrm{dd}, 11.0,14.0)$ & $130.5(d)$ & $6.15(1 \mathrm{H}, \mathrm{m})$ \\
\hline 15 & $138.5(d)$ & $6.19(1 \mathrm{H}, \mathrm{d}, 14.0)$ & $137.7(d)$ & $6.18(1 \mathrm{H}, \mathrm{d}, 15.4)$ \\
\hline 16 & $135.8(s)$ & & $135.5(\mathrm{~s})$ & \\
\hline 17 & $132.9(d)$ & $6.05(1 \mathrm{H}, \mathrm{m})$ & $132.3(d)$ & $6.05(1 \mathrm{H}, \mathrm{d}, 10.6)$ \\
\hline 18 & $124.8(d)$ & $6.17(1 \mathrm{H}, \mathrm{m})$ & $124.5(d)$ & $6.21(1 \mathrm{H}, \mathrm{m})$ \\
\hline 19 & $138.5(d)$ & $6.17(1 \mathrm{H}, \mathrm{m})$ & $137.9(d)$ & $6.21(1 \mathrm{H}, \mathrm{m})$ \\
\hline 20 & $138.3(\mathrm{~s})$ & & $137.7(\mathrm{~s})$ & \\
\hline 21 & $130.8(d)$ & $5.42(1 \mathrm{H}, \mathrm{dd}, 6.0,10.4)$ & $130.0(d)$ & $5.45(1 \mathrm{H}, \mathrm{m})$ \\
\hline 22 & $38.3(t)$ & $\begin{array}{l}2.23(1 \mathrm{H}, \mathrm{m}) \\
2.33(1 \mathrm{H}, \mathrm{q}, 12.0)\end{array}$ & $38.5(t)$ & $\begin{array}{l}2.28(1 \mathrm{H}, \mathrm{m}) \\
2.32(1 \mathrm{H}, \mathrm{m})\end{array}$ \\
\hline 23 & $48.0(d)$ & $4.06(1 \mathrm{H}, \mathrm{m})$ & $47.2(d)$ & $4.16(1 \mathrm{H}, \mathrm{m})$ \\
\hline 24 & $14.3(q)$ & $2.06(3 \mathrm{H}, \mathrm{s})$ & $14.2(q)$ & $2.09(3 \mathrm{H}, \mathrm{s})$ \\
\hline 25 & $23.3(q)$ & $1.51(3 \mathrm{H}, \mathrm{s})$ & $22.8(q)$ & $1.49(3 \mathrm{H}, \mathrm{s})$ \\
\hline 26 & $12.8(q)$ & $1.61(3 \mathrm{H}, \mathrm{s})$ & $12.9(q)$ & $1.66(3 \mathrm{H}, \mathrm{s})$ \\
\hline 27 & $12.8(q)$ & $1.64(3 \mathrm{H}, \mathrm{s})$ & $12.7(q)$ & $1.70(3 \mathrm{H}, \mathrm{s})$ \\
\hline 28 & $20.3(q)$ & $1.28(3 \mathrm{H}, \mathrm{d}, 6.7)$ & $20.7(q)$ & $1.32(3 \mathrm{H}, \mathrm{d}, 6.8)$ \\
\hline 29 & $61.4(q)$ & $3.52(3 \mathrm{H}, \mathrm{s})$ & $61.1(q)$ & $3.58(3 \mathrm{H}, \mathrm{s})$ \\
\hline $1-\mathrm{NH}$ & & $7.62(1 \mathrm{H}, \mathrm{d}, 10.4)$ & & \\
\hline $1^{\prime}$ & $99.9(d)$ & $4.89(1 \mathrm{H}, \mathrm{d}, 7.0)$ & & \\
\hline $2^{\prime}$ & $62.7(d)$ & $3.02(1 \mathrm{H}, \mathrm{t}, 7.0)$ & & \\
\hline $3^{\prime}$ & $69.2(d)$ & $3.85(1 \mathrm{H}, \mathrm{dd}, 7.0,8.0)$ & & \\
\hline $4^{\prime}$ & 77.1 (d) & $3.77(1 \mathrm{H}, \mathrm{ddd}, 4.2,8.0,8.0)$ & & \\
\hline $5^{\prime}$ & $63.0(\mathrm{t})$ & $\begin{array}{l}3.33(1 \mathrm{H}, \mathrm{dd}, 8.0,12.0) \\
4.05(1 \mathrm{H}, \mathrm{dd}, 4.2,12.0)\end{array}$ & & \\
\hline $6^{\prime}$ & $32.3(q)$ & $2.82(3 \mathrm{H}, \mathrm{s})$ & & \\
\hline $1 "$ & $101.1(d)$ & $4.69(1 \mathrm{H}, \mathrm{dd}, 1.5,9.1)$ & & \\
\hline $2 "$ & $30.5(\mathrm{t})$ & $\begin{array}{l}1.56(1 \mathrm{H}, \mathrm{m}) \\
1.98(1 \mathrm{H}, \mathrm{q}, 11.5)\end{array}$ & & \\
\hline $3 "$ & $24.4(t)$ & $\begin{array}{l}1.60(1 \mathrm{H}, \mathrm{m}) \\
2.25(1 \mathrm{H}, \mathrm{m})\end{array}$ & & \\
\hline $4 "$ & $59.7(d)$ & $2.86(1 \mathrm{H}, \mathrm{m})$ & & \\
\hline $5 "$ & $73.0(d)$ & $3.70(1 \mathrm{H}, \mathrm{dq}, 6.1,9.2)$ & & \\
\hline 6" & $18.5(q)$ & $1.36(3 \mathrm{H}, \mathrm{d}, 6.1)$ & & \\
\hline $7^{\prime \prime}$ & $31.0(q)$ & $2.66(3 \mathrm{H}, \mathrm{s})$ & & \\
\hline
\end{tabular}

Chemical shifts in ppm from TMS as an internal standard. 
Conformer-1/10 $R^{*}, 11 S^{*}$

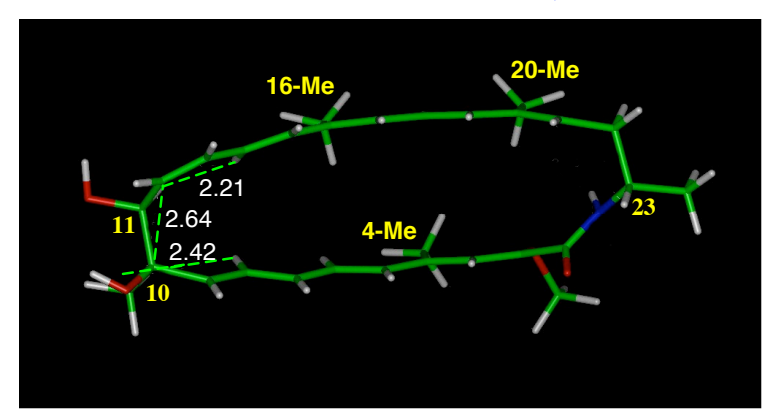

Conformer-3/10R*,11S*

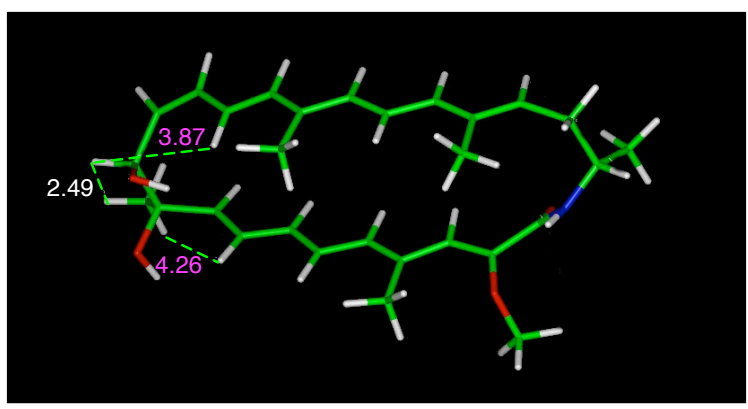

Conformer-2/10R*, 11S*

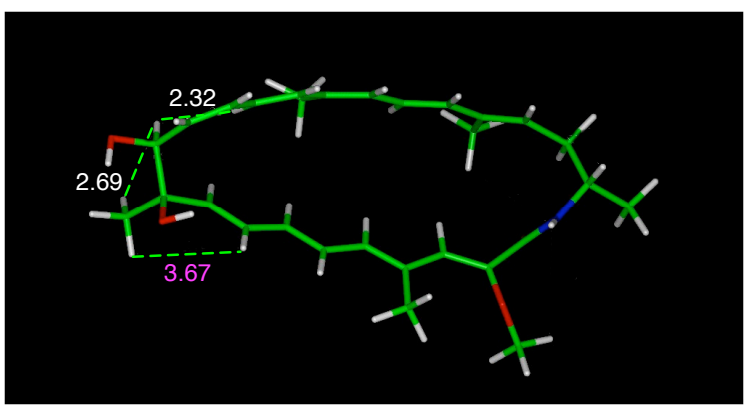

Conformer-4 / 10R*, $11 S^{*}$

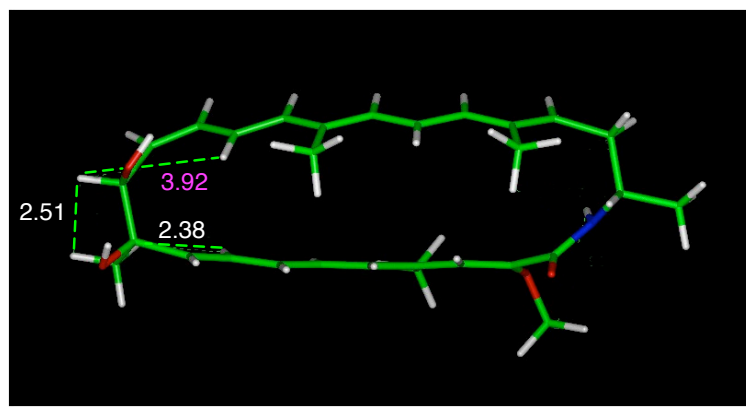

(B)

Conformer-1/10R*,11S*, 23S*

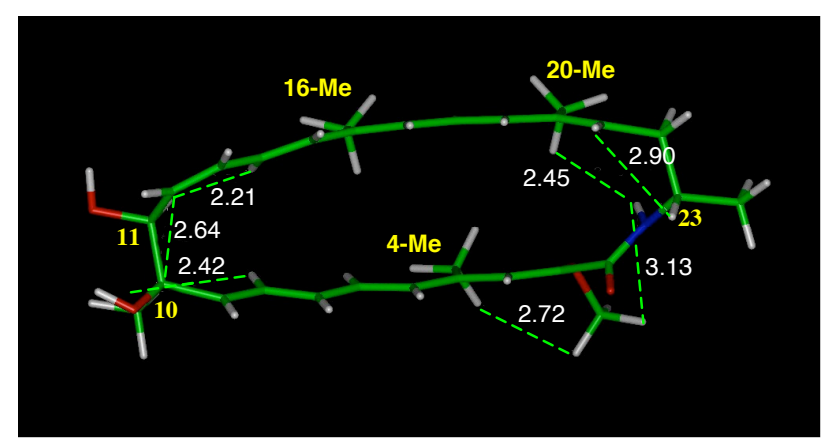

Conformer-1/10 $\boldsymbol{R}^{*}, 11 S^{*}, 23 \boldsymbol{R}^{*}$

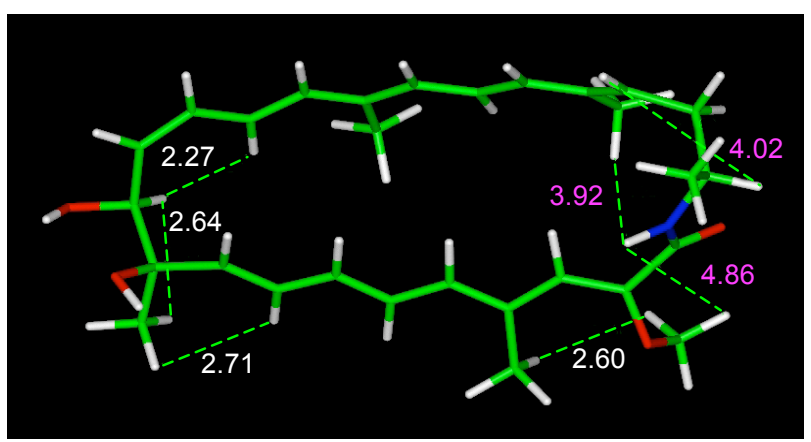

Figure S10 Optimized structure of incednine aglycon calculated by computations.

The relative stereochemistry of incednine aglycon was simulated with Discovery III programs. (A) The geometry of double bonds in aglycon and NOEs observed surrounding 4,16, and 20-Me allowed four types of conformers (1-4). Based on the NOEs and the coupling constant of $J_{11,12}$, the conformation of aglycon were suggested to be conformer-1/10R*, $11 S^{*}$. (B) The structures of $23 S^{*}$ or $23 R^{*}$ in conformer- 1 were modeled. The conformer-1/10R* $11 S^{*}, 23 S^{*}$ was in excellent agreement with the results of NOEs, while the other not. The data indicated showed the calculated-atomic distances $(\AA)$. The distance in white $(<3.4 \AA)$ shows the observable NOE, pink (> 3.4 $\AA$ ) not. 


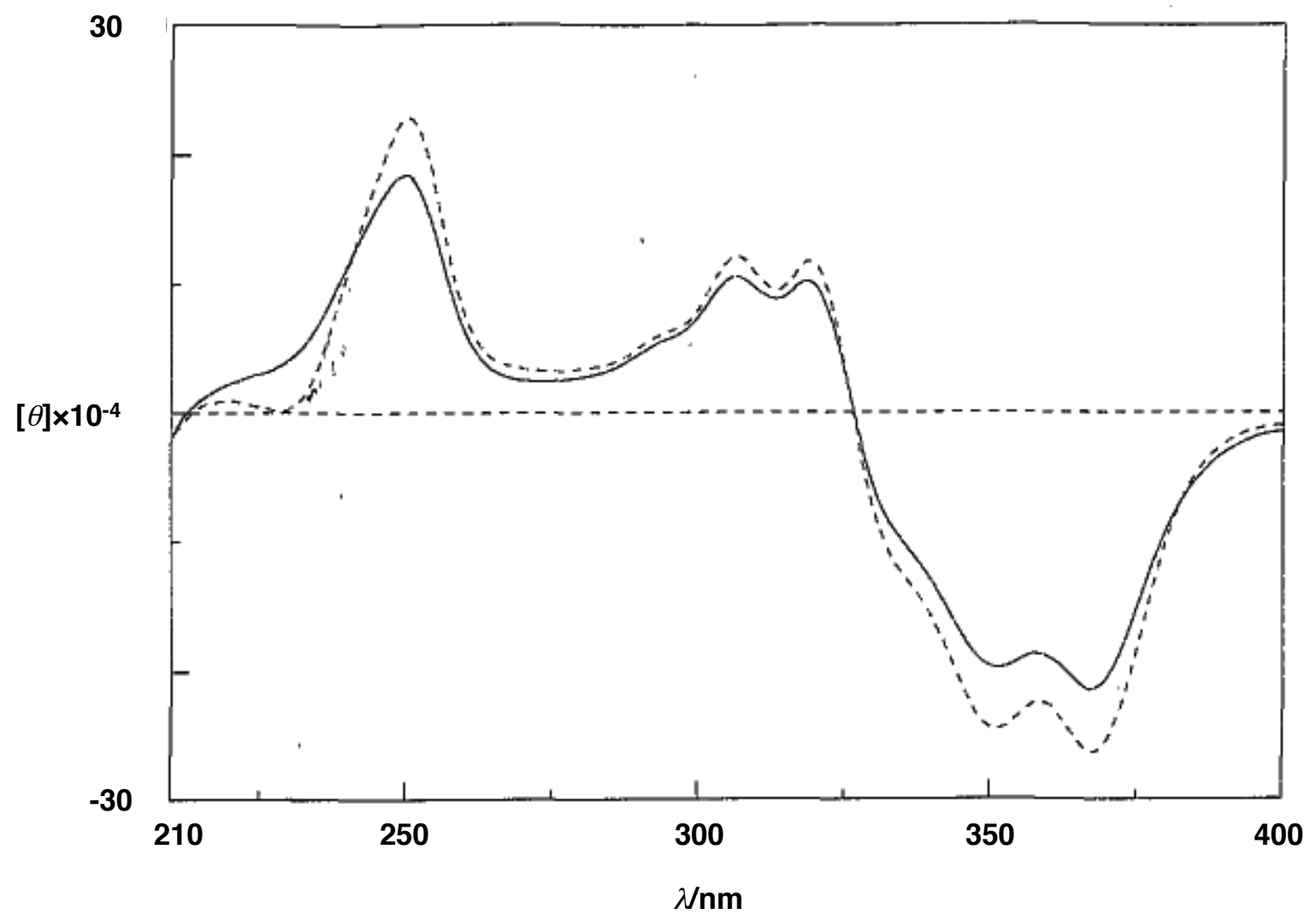

Figure $\mathrm{S} 11 \mathrm{CD}$ spectra of incednine $\cdot 2 \mathrm{HCl}$ and its aglycon.

Each $\mathrm{CD}$ spectrum was measured at $\mathrm{RT}$ in $\mathrm{MeOH}$ : incednine $2 \mathrm{HCl}(c 10[\mu \mathrm{g} / \mathrm{mL}]$, dashed line $)$; aglycon $(c 6[\mu \mathrm{g} / \mathrm{mL}]$, solid line) 


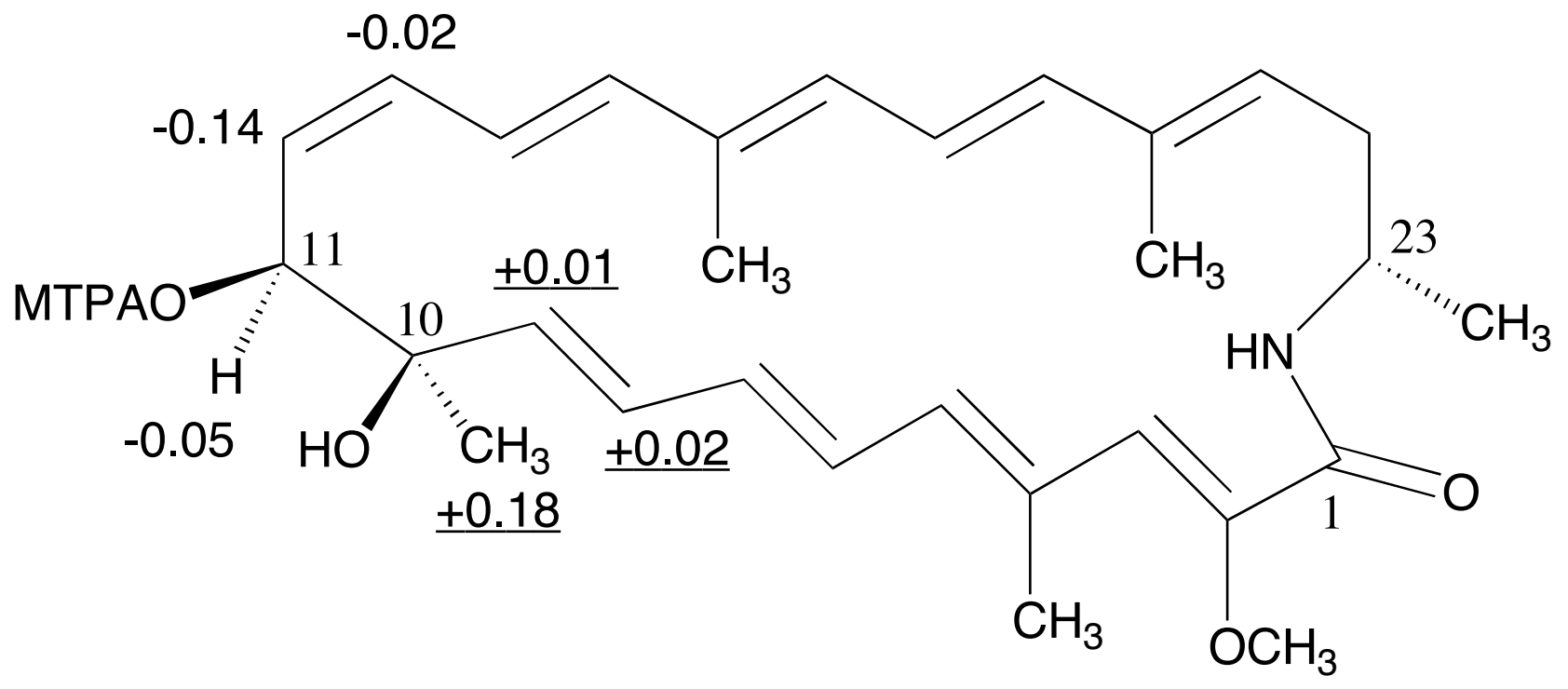

Figure S12 Incednine aglycone 11-O-MTPA ester with shifting values; $\Delta \delta(\mathrm{ppm})=\delta \mathrm{S}-\delta \mathrm{R}$ 
Table S2 ${ }^{1} \mathrm{H}$ and ${ }^{13} \mathrm{C}$ NMR data of R-MTPA (3) and S- MTPA (4) ester of aglycon

\begin{tabular}{|c|c|c|c|c|}
\hline \multirow[b]{2}{*}{ No. } & \multicolumn{2}{|r|}{$3\left(\mathrm{CDCl}_{3}, 25^{\circ} \mathrm{C}\right)$} & \multicolumn{2}{|r|}{$4\left(\mathrm{CDCl}_{3}, 25^{\circ} \mathrm{C}\right)$} \\
\hline & $\delta_{c}$ & $\delta_{\mathrm{H}}($ multiplicity, $J[\mathrm{~Hz}])$ & $\delta_{c}$ & $\delta_{\mathrm{H}}($ multiplicity, $J[\mathrm{~Hz}])$ \\
\hline 1 & $166.0(\mathrm{~s})$ & & $166.0(\mathrm{~s})$ & \\
\hline 2 & $146.5(\mathrm{~s})$ & & $146.6(\mathrm{~s})$ & \\
\hline 3 & $126.7(d)$ & $6.27(1 \mathrm{H}, \mathrm{brs})$ & $126.6(d)$ & $6.25(1 \mathrm{H}, \mathrm{brs})$ \\
\hline 4 & $132.2(\mathrm{~s})$ & & $132.2(\mathrm{~s})$ & \\
\hline 5 & $137.1(d)$ & $5.98(1 \mathrm{H}, \mathrm{d}, 11.1)$ & $137.1(d)$ & $5.96(1 \mathrm{H}, \mathrm{d}, 11.6)$ \\
\hline 6 & $128.5(d)$ & $6.43(1 \mathrm{H}, \mathrm{dd}, 11.1,14.3)$ & $128.4(d)$ & $6.43(1 \mathrm{H}, \mathrm{dd}, 11.6,15.0)$ \\
\hline 7 & $135.9(d)$ & $6.00(1 \mathrm{H}, \mathrm{dd}, 11.1,14.3)$ & $135.8(d)$ & $5.99(1 \mathrm{H}, \mathrm{dd}, 11.1,15.0)$ \\
\hline 8 & $129.8(d)$ & $6.18(1 \mathrm{H}, \mathrm{m})$ & $129.8(d)$ & $6.20(1 \mathrm{H}, \mathrm{m})$ \\
\hline 9 & $139.6(d)$ & $5.60(1 \mathrm{H}, \mathrm{d}, 16.3)$ & $139.7(d)$ & $5.61(1 \mathrm{H}, \mathrm{d}, 16.2)$ \\
\hline 10 & $75.2(\mathrm{~s})$ & & $75.0(\mathrm{~s})$ & \\
\hline 11 & $79.4(d)$ & $5.63(1 \mathrm{H}, \mathrm{d}, 9.8)$ & 79.8 (d) & $5.58(1 \mathrm{H}, \mathrm{d}, 10.0)$ \\
\hline 12 & $122.9(d)$ & $5.43(1 \mathrm{H}, \mathrm{t}, 9.8)$ & $123.0(\mathrm{~d})$ & $5.29(1 \mathrm{H}, \mathrm{t}, 10.0)$ \\
\hline 13 & $133.4(d)$ & $6.30(1 \mathrm{H}, \mathrm{dd}, 9.8,11.4)$ & $133.2(d)$ & $6.28(1 \mathrm{H}, \mathrm{dd}, 10.0,11.0)$ \\
\hline 14 & $123.5(d)$ & $6.15(1 \mathrm{H}, \mathrm{m})$ & $123.6(d)$ & $6.16(1 \mathrm{H}, \mathrm{m})$ \\
\hline 15 & $139.1(d)$ & $6.23(1 \mathrm{H}, \mathrm{d}, 15.0)$ & $138.9(d)$ & $6.22(1 \mathrm{H}, \mathrm{d}, 14.8)$ \\
\hline 16 & $134.5(\mathrm{~s})$ & & $134.5(\mathrm{~s})$ & \\
\hline 17 & $132.9(d)$ & $6.06(1 \mathrm{H}, \mathrm{d}, 10.4)$ & $132.8(d)$ & $6.06(1 \mathrm{H}, \mathrm{d}, 10.4)$ \\
\hline 18 & $123.8(d)$ & $6.19(1 \mathrm{H}, \mathrm{m})$ & $123.8(d)$ & $6.19(1 \mathrm{H}, \mathrm{m})$ \\
\hline 19 & $137.9(d)$ & $6.22(1 \mathrm{H}, \mathrm{m})$ & $137.8(d)$ & $6.23(1 \mathrm{H}, \mathrm{m})$ \\
\hline 20 & 136.9 (s) & & $136.9(\mathrm{~s})$ & \\
\hline 21 & $129.7(d)$ & $5.50(1 \mathrm{H}, \mathrm{dd}, 5.2,11.5)$ & $129.7(d)$ & $5.50(1 \mathrm{H}, \mathrm{dd}, 5.3,11.0)$ \\
\hline 22 & $38.4(t)$ & $\begin{array}{l}2.20(1 \mathrm{H}, \mathrm{q}, 11.5) \\
2.31(1 \mathrm{H}, \mathrm{m})\end{array}$ & $38.4(t)$ & $\begin{array}{l}2.20(1 \mathrm{H}, \mathrm{q}, 11.0) \\
2.31(1 \mathrm{H}, \mathrm{m})\end{array}$ \\
\hline 23 & $46.5(d)$ & $4.27(1 \mathrm{H}, \mathrm{m})$ & $46.5(d)$ & $4.26(1 \mathrm{H}, \mathrm{m})$ \\
\hline 24 & $13.9(q)$ & $2.06(3 \mathrm{H}, \mathrm{s})$ & $14.0(q)$ & $2.07(3 \mathrm{H}, \mathrm{s})$ \\
\hline 25 & $23.1(q)$ & $1.30(3 \mathrm{H}, \mathrm{s})$ & $23.4(q)$ & $1.48(3 \mathrm{H}, \mathrm{s})$ \\
\hline 26 & $12.7(q)$ & $1.67(3 \mathrm{H}, \mathrm{s})$ & $12.5(q)$ & $1.67(3 \mathrm{H}, \mathrm{s})$ \\
\hline 27 & $12.5(q)$ & $1.67(3 \mathrm{H}, \mathrm{s})$ & $12.7(q)$ & $1.67(3 \mathrm{H}, \mathrm{s})$ \\
\hline 28 & $21.1(q)$ & $1.30(3 \mathrm{H}, \mathrm{d}, 6.0)$ & $21.1(q)$ & $1.30(3 \mathrm{H}, \mathrm{d}, 6.6)$ \\
\hline 29 & $61.2(q)$ & $3.56(3 \mathrm{H}, \mathrm{s})$ & $61.2(q)$ & $3.57(3 \mathrm{H}, \mathrm{s})$ \\
\hline $1-\mathrm{NH}$ & & $5.90(1 \mathrm{H}, \mathrm{d}, 11.0)$ & & $5.88(1 \mathrm{H}, \mathrm{d}, 10.6)$ \\
\hline MTPA, C=O & 165.7 (s) & & $165.8(\mathrm{~s})$ & \\
\hline MTPA, C & 84.5 (s) & & $85.0(\mathrm{~s})$ & \\
\hline MTPA, OMe & $55.4(q)$ & $3.57(3 \mathrm{H}, \mathrm{s})$ & $55.5(q)$ & $3.57(3 \mathrm{H}, \mathrm{s})$ \\
\hline MTPA, ph & $132.4(\mathrm{~s})$ & & 131.8 (s) & \\
\hline MTPA, ph & $129.5(d)$ & $7.42(1 \mathrm{H}, \mathrm{m})$ & $129.8(d)$ & $7.42(1 \mathrm{H}, \mathrm{m})$ \\
\hline MTPA, ph & $128.4(d)$ & $7.42(1 \mathrm{H}, \mathrm{m})$ & $128.5(d)$ & $7.42(1 \mathrm{H}, \mathrm{m})$ \\
\hline MTPA, ph & $127.7(d)$ & $7.42(1 \mathrm{H}, \mathrm{m})$ & $127.7(d)$ & $7.42(1 \mathrm{H}, \mathrm{m})$ \\
\hline MTPA, ph & $127.3(d)$ & $7.55(2 \mathrm{H}, \mathrm{m})$ & $127.6(d)$ & $7.53(2 \mathrm{H}, \mathrm{m})$ \\
\hline
\end{tabular}

Chemical shifts in ppm from TMS as an internal standard. 


\section{$\underline{\text { D form }}$}

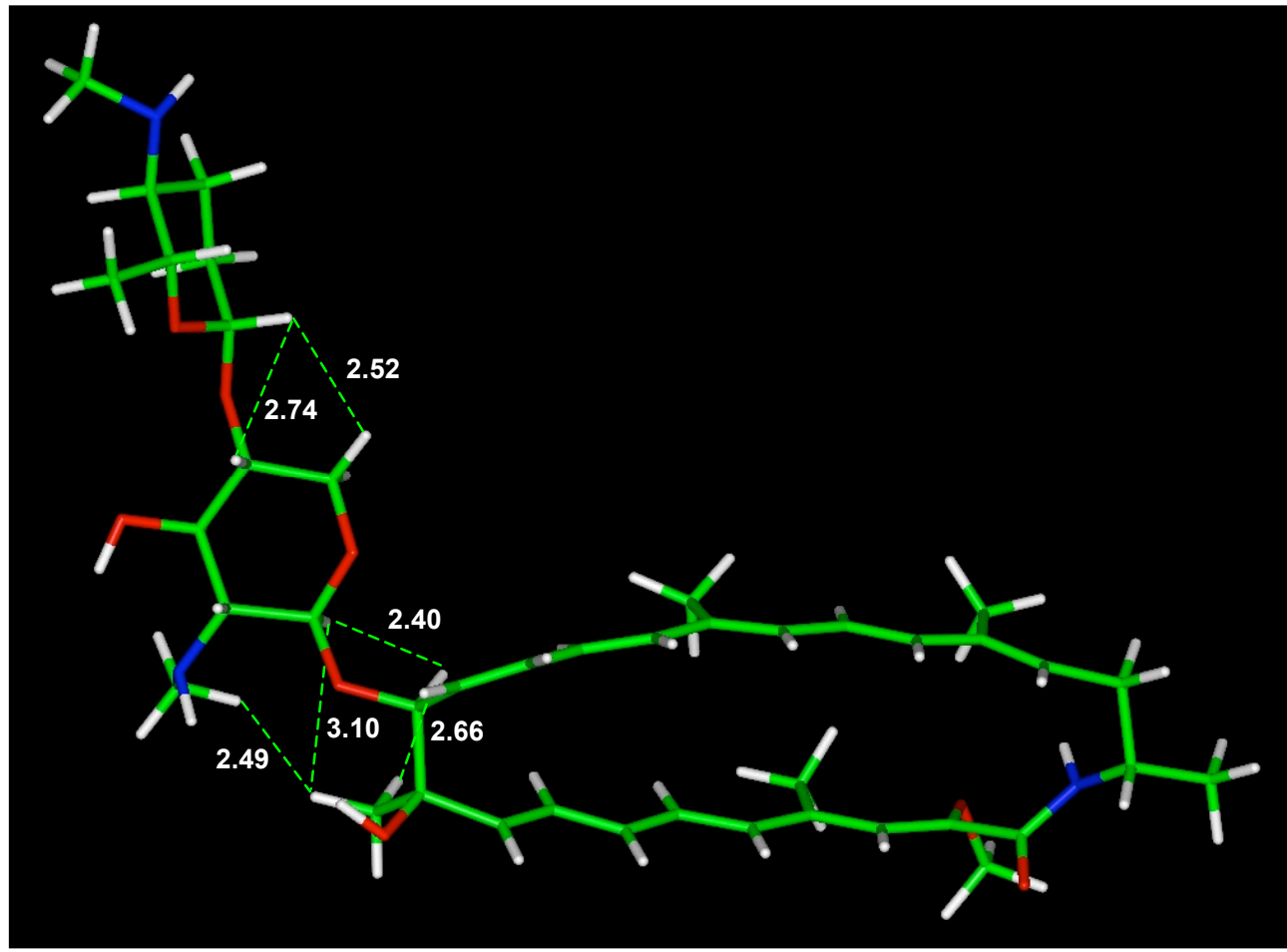

\section{L form}

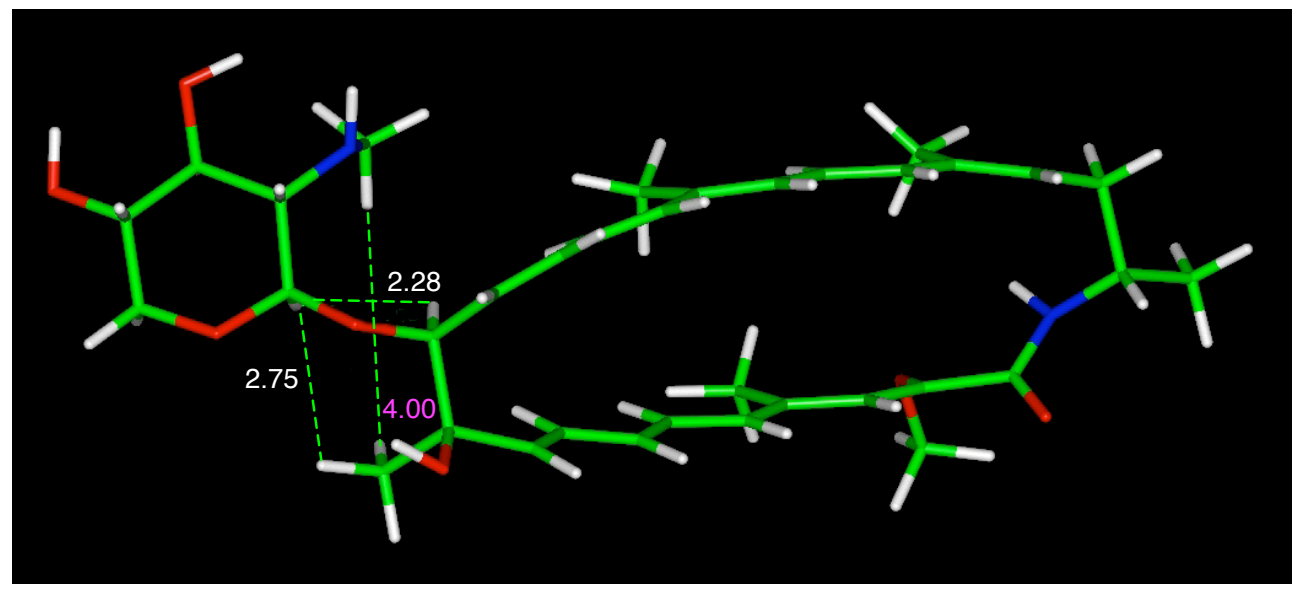

Figure S13 D-form of Aminosugar (A) met the experimentally-observed NOEs.

The streochemistry of $\mathrm{H}-1^{\prime}$ in aminosugar $(\mathrm{A})$ was confirmed by computations. Two types of structures were modeled and the atomic distances $(\AA)$ were calculated as indicated. The distance in white $(<3.4 \AA)$ shows the observable NOE, pink $(>3.4 \AA)$ not. 


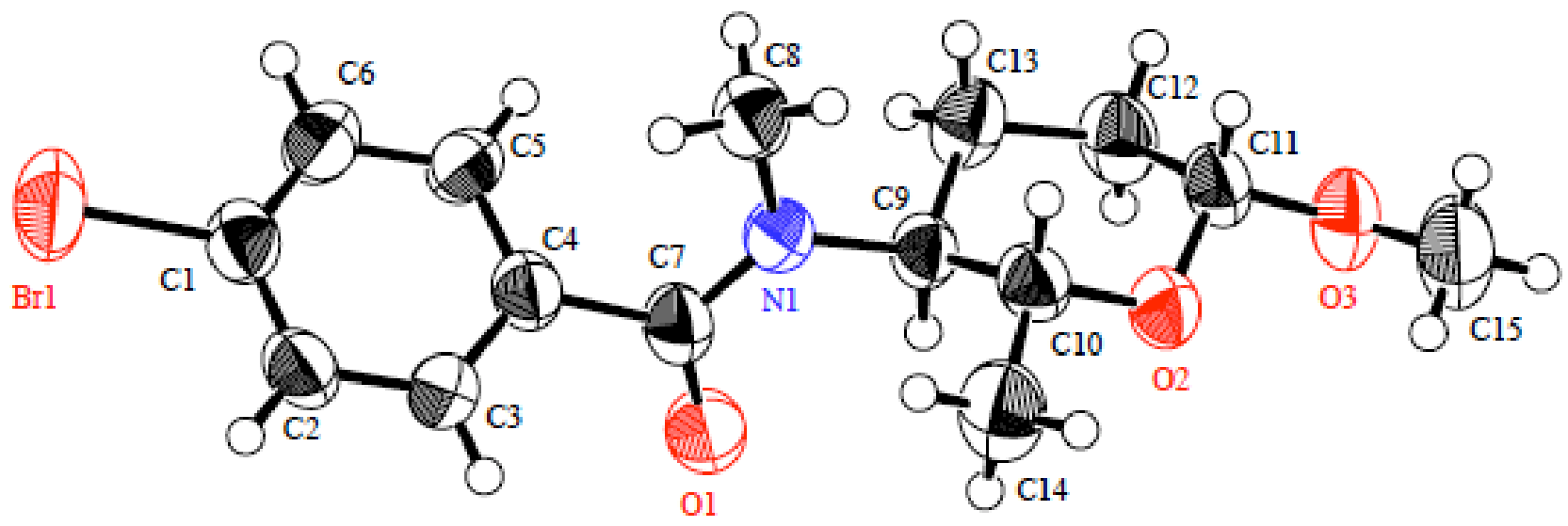

Figure S14 ORTEP drawing of methyl N-(4-bromobenzoyl)-2,3,4,6-tetradeoxy4-methylamino- $\beta$-D-erythro-hexopyranoside (5) 
Table $53{ }^{1} \mathrm{H}$ and ${ }^{13} \mathrm{C}$ NMR data of Methyl $\mathrm{N}$-(4-bromobenzoyl)-2,3,4,6,tetradeoxy-4-methylamino- $\beta$-D-erythro-hexopyranoside (5)

\begin{tabular}{ccl}
\hline No. & $\delta_{\mathrm{C}}$ & \multicolumn{1}{c}{$\delta_{\mathrm{H}}$ (multiplicity, $\left.J[\mathrm{~Hz}]\right)$} \\
\hline 1 & $102.4(\mathrm{~d})$ & $4.30(1 \mathrm{H}, \mathrm{d}, 9.5)$ \\
2 & $26.0(\mathrm{t})$ & $1.42(1 \mathrm{H}, \mathrm{m}), 1.91(1 \mathrm{H}, \mathrm{m})$ \\
3 & $30.9(\mathrm{t})$ & $1.81(1 \mathrm{H}, \mathrm{m})$ \\
4 & $60.0(\mathrm{~d})$ & $3.33(1 \mathrm{H}, \mathrm{m}, 9.3)$ \\
5 & $72.1(\mathrm{~d})$ & $3.65(1 \mathrm{H}, \mathrm{dq}, 6.2,9.3)$ \\
6 & $17.9(\mathrm{q})$ & $1.13(3 \mathrm{H}, \mathrm{d}, 6.2)$ \\
7 & $27.7(\mathrm{q})$ & $2.92(3 \mathrm{H}, \mathrm{s})$ \\
$1-\mathrm{OCH}{ }_{3}$ & $56.2(\mathrm{q})$ & $3.43(3 \mathrm{H}, \mathrm{s})$ \\
$\mathrm{C}=\mathrm{O}$ & $171.8(\mathrm{~s})$ & \\
$\mathrm{Ph}$ & $135.5(\mathrm{~s})$ & \\
$\mathrm{Ph}$ & $132.0(\mathrm{~d})$ & $7.54(2 \mathrm{H}, \mathrm{d}, 7.8)$ \\
$\mathrm{Ph}$ & $128.0(\mathrm{~d})$ & $7.19(2 \mathrm{H}, \mathrm{d}, 8.1)$ \\
$\mathrm{Ph}$ & $123.8(\mathrm{~s})$ & \\
\hline
\end{tabular}

* Chemical shifts in ppm from TMS as an internal standard.

* This compound exsited in two types of isomers (2:1) in the solution, likely due to the geometry of amide. The spectral data of major isomer were presented in this column. 
(ii) Biological activity

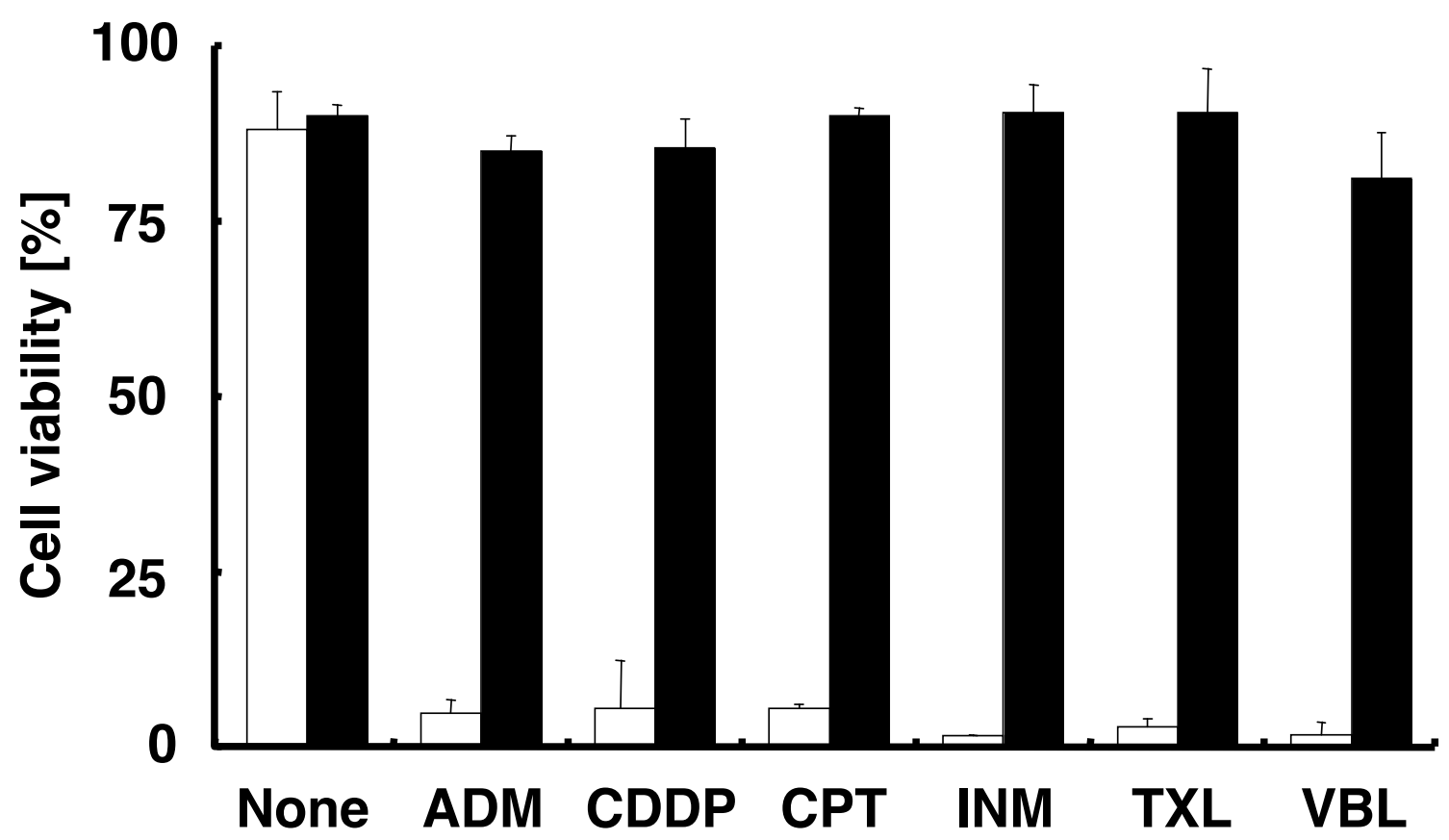

Figure S15 Overexpression of Bcl-xL protected Ms-1 cells from anti-tumor druginduced apoptosis.

Ms-1/neo cells (open squares) and Ms-1/Bcl-xL cells (closed squares) were treated with compounds indicated for $48 \mathrm{~h}$. Cell viability was assessed by trypan blue dye exclusion assay. Values are means of three samples: bars, SD. (adriamycin; ADM, $3 \mu \mathrm{g} / \mathrm{mL}$, cisplatin; CDDP, $100 \mu \mathrm{g} / \mathrm{mL}$, camptothecin; CPT, $3 \mu \mathrm{g} / \mathrm{mL}$, inostamycin; INM, $0.3 \mu \mathrm{g} / \mathrm{mL}$, taxol; TXL, $100 \mathrm{ng} / \mathrm{mL}$, vinblastine; VBL, $10 \mathrm{ng} / \mathrm{mL}$.) 
Adriamycin

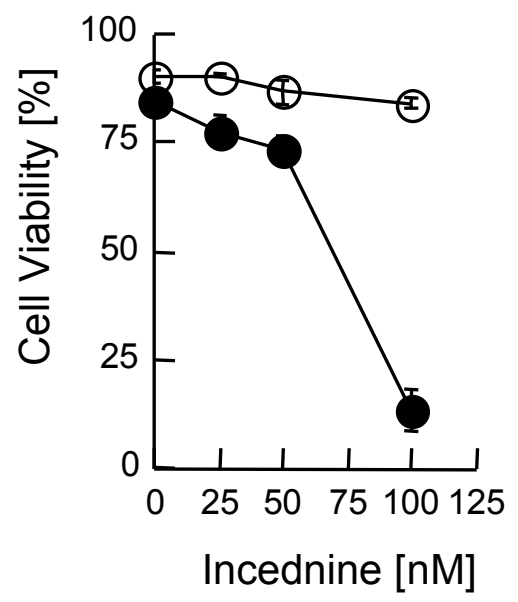

Inostamycin

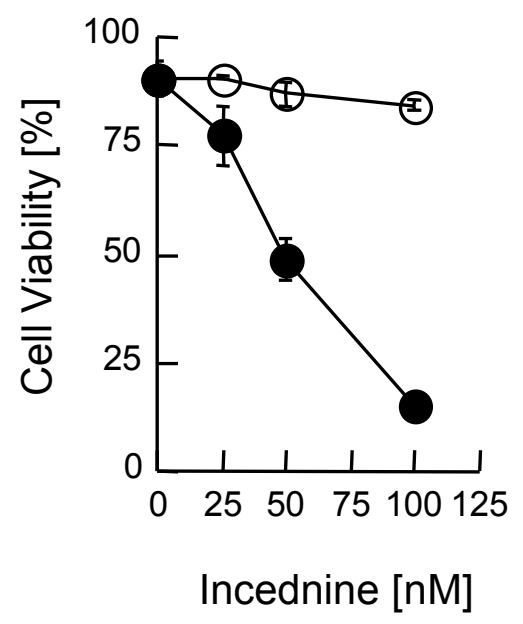

Camptothecin

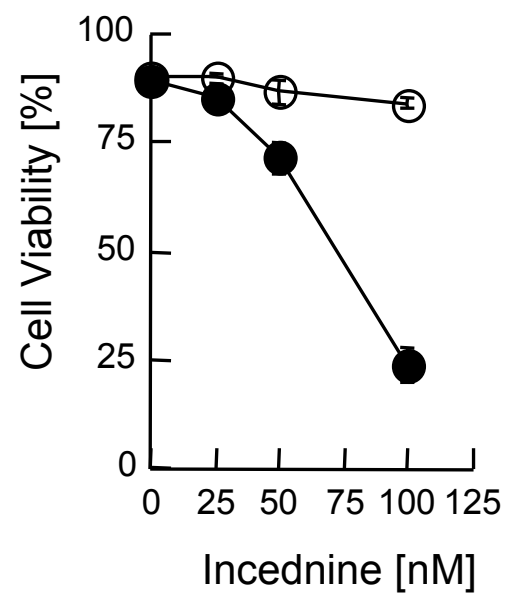

Taxol

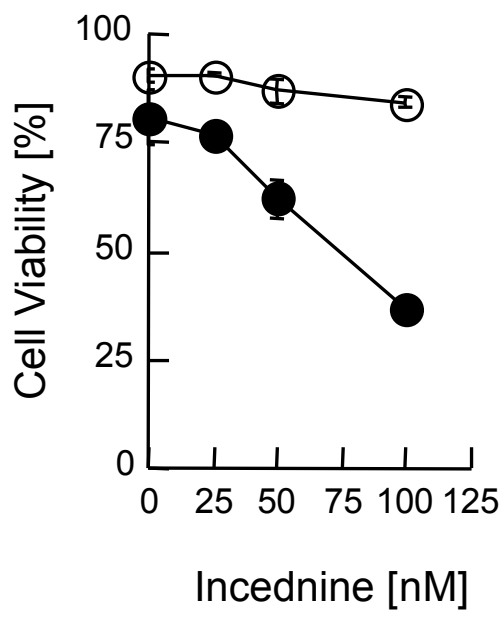

Cisplatin

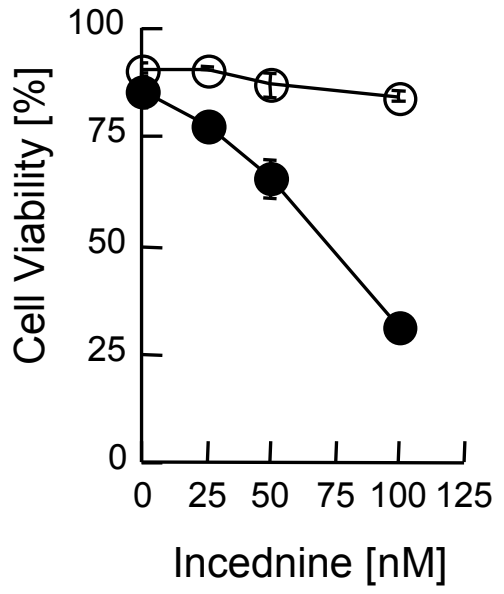

Vinblastine

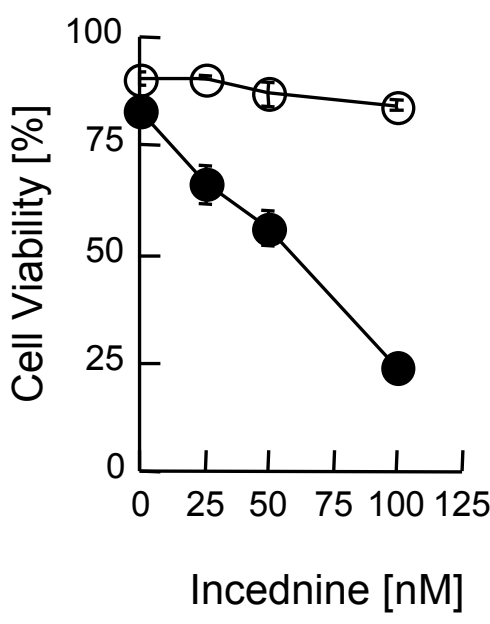

Figure S16 Incednine overcomes the anti-apoptotic function of Bcl-xL against anti-tumor drug-induced apoptosis in $\mathrm{Ms}-1 / \mathrm{Bcl}-\mathrm{xL}$ cells.

Ms-1/Bcl-xL cells were treated with incednine in combination with several types of anti-tumor drugs as indicated for $48 \mathrm{~h}$ (incednine alone; open circle, combination; closed circle). Cell viability was assessed by trypan blue dye exclusion assay. Values are means of three samples: bars, SD. (adriamycin; $3 \mu \mathrm{g} / \mathrm{mL}$, cisplatin; $100 \mu \mathrm{g} / \mathrm{mL}$, camptothecin; $3 \mu \mathrm{g} / \mathrm{mL}$ inostamycin; $0.3 \mu \mathrm{g} / \mathrm{mL}$, taxol; $100 \mathrm{ng} / \mathrm{mL}$, vinblastine; $10 \mathrm{ng} / \mathrm{mL}$.) 


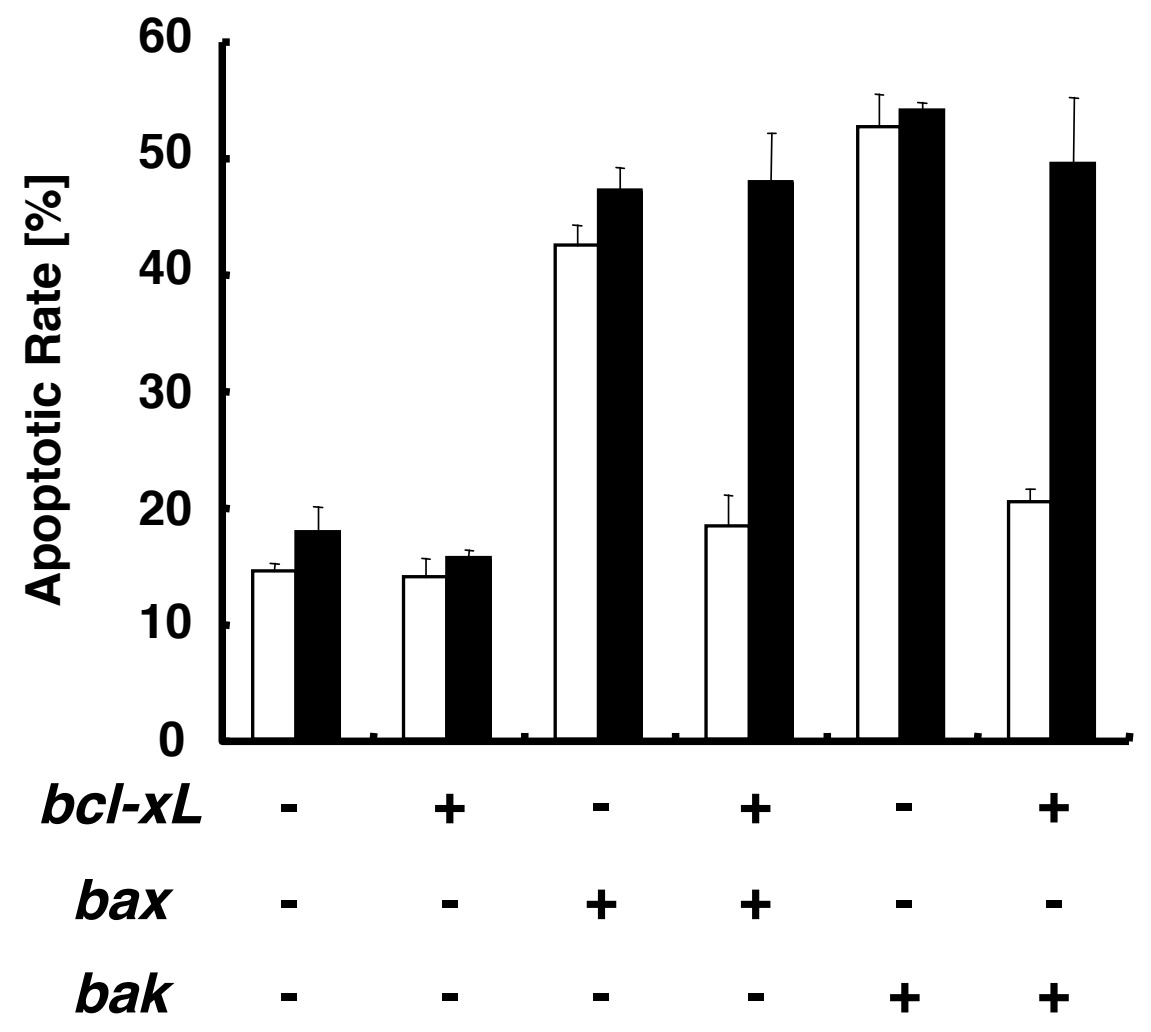

Figure S17 Effect of incednine on anti-apoptotic function of Bcl-xL in Bax- or Bak-induced apoptosis in HEK293T cells.

HEK293T cells were transiently co-transfected with pCl-neo plasmids encoding Bax or Bak and $\mathrm{Bcl}-\mathrm{xL}$. The total amounts of DNA were normalized with $\mathrm{pCl}$-neo empty vector. After $5 \mathrm{~h}$ incubation, cells were treated with (closed squares) or without (open squares) $60 \mathrm{nM}$ incednine for $48 \mathrm{~h}$. Apoptotic rate was assessed by trypan blue dye exclusion assay. Values are means of three samples: bars, SD. 


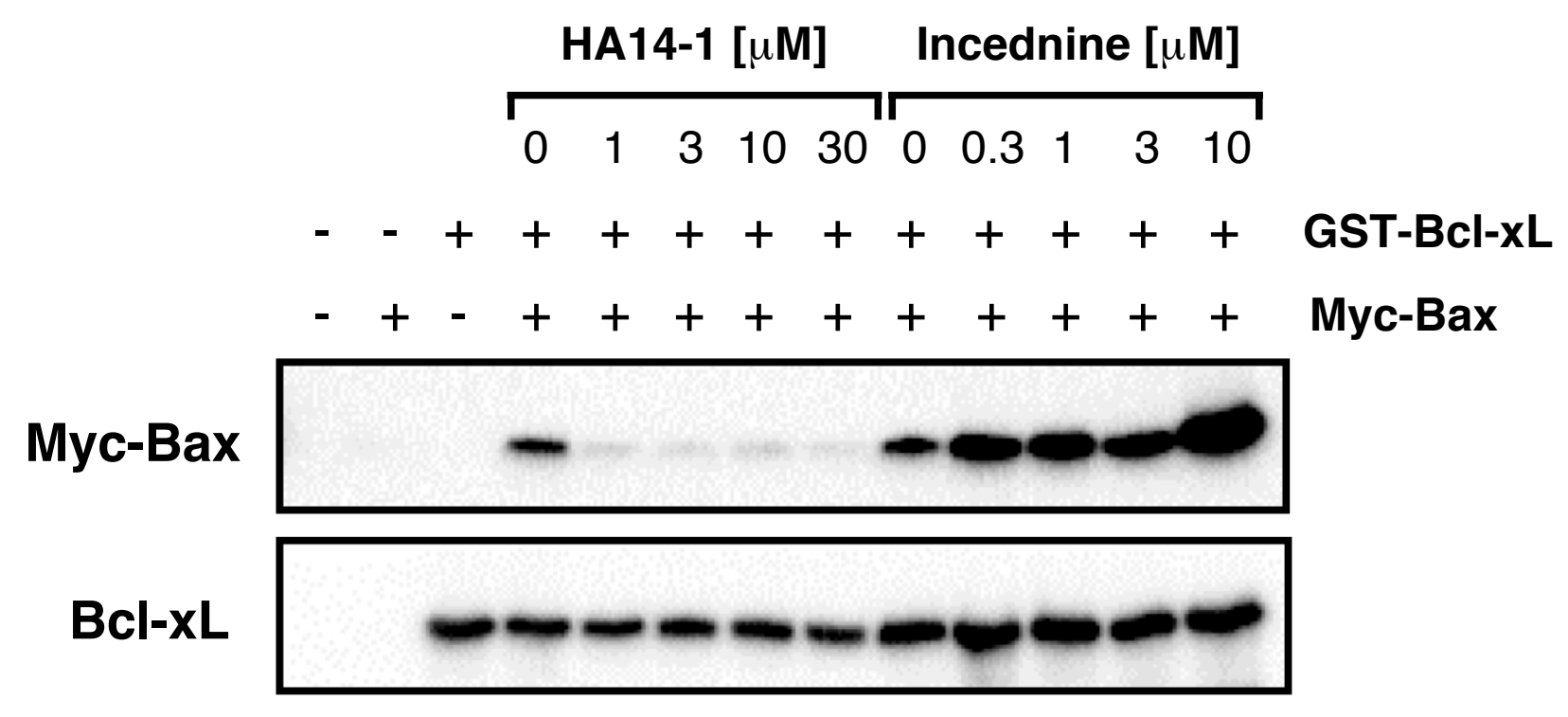

Figure S18 Effect of incednine on heterodimerization of Bcl-xL and Bax in vitro.

The lysate from HEK 293T cells transiently transfected with pCl-myc-bax $(50 \mu \mathrm{g})$ was incubated with recombinant GST-Bcl-xL $(1 \mu \mathrm{g})$ and glutathione-sepharose 4B beads in the presence or absence of indicated concentrations of incednine or HA14-1 for $2 \mathrm{~h}$ at $4^{\circ} \mathrm{C}$. The amount of Bax bound to $\mathrm{Bcl}-\mathrm{xL}$ was determined by immunoblot analysis with anti-Myc antibody. 